Check for updates

Cite this: RSC Adv., 2018, 8, 28216

\title{
One pot synthesis of two cobalt(III) Schiff base complexes with chelating pyridyltetrazolate and exploration of their bio-relevant catalytic activities $\dagger$
}

\author{
Kousik Ghosh, ${ }^{a}$ Abhisek Banerjee, ${ }^{a}$ Antonio Bauzá, (D) ${ }^{\mathrm{b}}$ Antonio Frontera (DD *b \\ and Shouvik Chattopadhyay (D) *a
}

Two new cobalt(II) tetrazolato complexes $\left[\mathrm{Co}\left(\mathrm{L}^{1}\right)(\mathrm{PTZ})\left(\mathrm{N}_{3}\right)\right](1)$ and $\left[\mathrm{Co}\left(\mathrm{L}^{2}\right)(\mathrm{PTZ})\left(\mathrm{N}_{3}\right)\right](2)\left\{\right.$ where $\mathrm{H}_{2} \mathrm{~L}^{1}=2((3-$ (methylamino)propylimino)methyl)-6-methoxyphenol, $\mathrm{H}_{2} \mathrm{~L}^{2}=2((3$-(dimethylamino)propylimino)methyl)6-ethoxyphenol and HPTZ = 5-(2-pyridyl)tetrazole\}, have been synthesized via in situ 1,3-dipolar cycloaddition reaction of 2-cyanopyridine and sodium azide in the presence of cobalt(I) nitrate hexahydrate and respective Schiff bases in the open atmosphere. The structures of both complexes have been confirmed by single crystal X-ray diffraction studies. Features of noncovalent interactions in the solid state of both complexes have been studied by means of DFT and MEP calculations and characterized using Bader's theory of "atoms in molecules" (AIM). These complexes act as biomimetic catalysts promoting the aerobic oxidation of 3,5-di-tert-butylcatechol (3,5-DTBC) to the corresponding o-benzoquinone at room temperature. The reaction follows Michaelis-Menten enzymatic reaction kinetics with turnover numbers of $\sim 0.030 \mathrm{~s}^{-1}$ in an acetonitrile-methanol (2:1) mixture. Both complexes are also reactive towards aerobic oxidation of 0 -aminophenol in acetonitrile-methanol $(2: 1)$ with turnover numbers $\sim 0.095 \mathrm{~s}^{-1}$

Received 9th April 2018

Accepted 16th July 2018

DOI: $10.1039 / \mathrm{c} 8 \mathrm{ra03035a}$

rsc.li/rsc-advances

\section{Introduction}

Transition metals are known to play various significant roles in living systems. ${ }^{1}$ They are present in many metalloenzymes and metalloproteins and the roles of these enzymes and proteins are primarily dependant on these metal ions. ${ }^{2}$ If the metal ions are removed from these enzymes, the corresponding apo-enzymes are found to lose their catalytic activity, either partially or completely. ${ }^{3}$ The group of enzymes that is capable of processing molecular oxygen under ambient conditions has attracted the attention of synthetic inorganic chemists and they designed many catalysts acting as mimics of various oxidase enzymes. ${ }^{4}$ Mimics of these oxidase metalloenzymes are of particular interest for the development of bio-inspired catalysts for oxidation reactions. ${ }^{5}$ For example, atmospheric dioxygen is used by catechol oxidase, a type- 3 di-copper enzyme, for the oxidation of catechols to ortho-quinones. ${ }^{6} \mathrm{~A}$ variety of di-

${ }^{a}$ Department of Chemistry, Inorganic Section, Jadavpur University, Kolkata, 700032, India. E-mail: shouvik.chem@gmail.com; Tel: +913324572147

${ }^{b}$ Departament de Química, Universitat de les IllesBalears, Crta. De Valldemossa $\mathrm{km}$ 7.5, 07122 Palma (Baleares), Spain. E-mail: toni.frontera@uib.es

$\dagger$ Electronic supplementary information (ESI) available: CCDC 1548132 and 1548133 contain the supplementary crystallographic data for $\mathbf{1}$ and 2 respectively. For ESI and crystallographic data in CIF or other electronic format see DOI: $10.1039 / \mathrm{c} 8 \mathrm{ra03035a}$
copper(II), di-nickel(II) and manganese(II/III) containing functional models of these metalloenzymes have been shown to mediate such catechol oxidation. ${ }^{7}$ Phenoxazinone synthase, another multicopper oxidase enzyme, is known to catalyze the oxidative condensation of two molecules of a substituted $o$ aminophenol to the phenoxazinone chromophore. ${ }^{8}$ Many transition metal complexes of Schiff bases have been showing to have the ability to mimic these two enzyme. ${ }^{9}$ Focusing to cobalt(III) Schiff base complexes, extensive attention into their metallo-organic and coordination chemistry arises from their synthetic accessibility, fascinating structural features and diverse range of applications in photochemistry, ${ }^{10}$ electrochromism, ${ }^{11}$ and catalysis. ${ }^{12}$ They also have significant biological applications..$^{13}$ Cobalt(III) Schiff base complexes have been used as precursor for the synthesis of $\mathrm{Co}_{3} \mathrm{O}_{4}$ nanoparticles via thermal decomposition method. ${ }^{14}$

The chemistry of tetrazoles and their complexes, on the other hand, has received great attention now-a-days ${ }^{15}$ for their wide range of applications in coordination chemistry, ${ }^{16}$ medicinal chemistry ${ }^{17}$ and material science. ${ }^{18}$ Although several synthetic methods have been reported so far, synthesis by 1,3-dipolar cycloaddition of cyanopyridine/cyanopyrazines and metal coordinated azide is probably the best method. ${ }^{19}$ However, although few metal tetrazolate complexes containing Schiff bases as blocking ligands exist in literature, ${ }^{20}$ best to our 
knowledge there is no report for the synthesis of any cobalt(III) tetrazolate complexes with Schiff base coligands. Keeping this in mind, we plan to synthesize and characterize few cobalt(III) tetrazolato complexes with Schiff base co-ligands. Supramolecular extended networks generated through weak non-covalent forces (hydrogen bonding and $\mathrm{C}-\mathrm{H} \cdots \pi$ interaction) have also been examined in detail using several theoretical models at the DFT-D3 level, estimating the contribution of each interaction to the formation of the assembly. Finally, catechol oxidase and phenoxazinone synthase like activities of both cobalt(III) tetrazolato complexes have been explored.

\section{Experimental section}

\section{Materials}

All starting materials were commercially available, reagent grade, and used as purchased from Sigma-Aldrich without further purification. The reactions and all manipulations of the samples were carried out under aerobic conditions.

Caution!!! Metal complexes containing azides and organic ligands are potentially explosive. Only a small amount of the material should be prepared and they should be handled with care. The experimental work is safe with the proper precautions.

\section{Preparations}

Preparation of $\left[\mathbf{C o}\left(\mathbf{L}^{\mathbf{1}}\right)(\mathbf{P T Z})\left(\mathbf{N}_{3}\right)\right]$ (1). A methanol solution of (20 mL) $N$-methyl-1,3-diaminopropane $(0.11 \mathrm{~mL}, 1 \mathrm{mmol})$ and 3methoxysalicylaldehyde (152 $\mathrm{mg}, 1 \mathrm{mmol}$ ) was refluxed for $c a$. $1 \mathrm{~h}$ to form a Schiff base, $\mathrm{HL}^{1}$. A methanol solution $(5 \mathrm{~mL})$ of 2 cyanopyridine ( $1 \mathrm{mmol}, 105 \mathrm{mg}$ ) was then added to it, followed by the addition of a methanol solution $(5 \mathrm{~mL})$ of cobalt(II) nitrate hexahydrate $(1 \mathrm{mmol}, 291 \mathrm{mg})$ with constant stirring. A solution of sodium azide ( $1 \mathrm{mmol}, 65 \mathrm{mg}$ ) in methanol-water was added to it and the stirring was continued for additional $2 \mathrm{~h}$. A dark brown crystalline material was started to separate out on standing the resulting solution at room temperature. It was collected by filtration and dissolved in acetonitrile. Dark brown single crystals, suitable for X-ray diffraction started to separate after $c a .7$ days.

Yield: $347 \mathrm{mg}(\sim 74 \%)$; based on cobalt(III). Anal. calc. for $\mathrm{C}_{18} \mathrm{H}_{21} \mathrm{CoN}_{10} \mathrm{O}_{2}$ (FW = 468.38): C, 46.12; H, 4.48; N, 29.89\%. Found: C, 46.2; H, 4.4; N, 29.9\%. FT-IR $\left(\mathrm{KBr}, \mathrm{cm}^{-1}\right): 3182\left(v_{\mathrm{N}-\mathrm{H}}\right)$, $2990-2890\left(v_{\mathrm{C}-\mathrm{H}}\right), 2022\left(v_{\mathrm{N} 3}\right), 1632\left(v_{\mathrm{C}=\mathrm{N}}\right), 1472\left(v_{\text {tetrazolate }}\right), 1446$ $\left(v_{\text {tetrazolate }}\right)$. UV-Vis, $\lambda_{\max }(\mathrm{nm}),\left[\varepsilon_{\max }\left(\mathrm{dm}^{3} \mathrm{~mol}^{-1} \mathrm{~cm}^{-1}\right)\right]$ $\left(\mathrm{CH}_{3} \mathrm{CN}\right), 670\left(1.12 \times 10^{2}\right), 345\left(6.16 \times 10^{3}\right), 240\left(3.95 \times 10^{4}\right)$. Magnetic moment: 0.095 BM (diamagnetic).

Preparation of $\left[\mathbf{C o}\left(\mathbf{L}^{2}\right)(\mathbf{P T Z})\left(\mathbf{N}_{3}\right)\right]$ (2). Complex 2 was prepared using a similar method as that used for complex 1 except that $\mathrm{HL}^{2}$ was used instead of $\mathrm{HL}^{1}$. $\mathrm{HL}^{2}$ was synthesized by refluxing a methanol solution of $N, N$-dimethyl-1,3-diaminopropane (0.125 $\mathrm{mL}, 1 \mathrm{mmol}$ ) and 3-ethoxysalicylaldehyde (166 mg, 1 $\mathrm{mmol}$ ) for $\mathrm{ca} .1 \mathrm{~h}$. X-ray quality dark brown single crystals started to grow from acetonitrile solution after $c a .7$ days.

Yield: $360 \mathrm{mg}(\sim 72 \%)$; based on cobalt(III). Anal. calc. for $\mathrm{C}_{20} \mathrm{H}_{25} \mathrm{CoN}_{10} \mathrm{O}_{2}$ (FW = 496.43): C, 48.35; H, 5.04; N, 28.20\%. Found: C, 48.4; H, 5.0; N, 28.3\%. FT-IR (KBr, $\left.\mathrm{cm}^{-1}\right): 3000-2928$
$\left(v_{\mathrm{C}-\mathrm{H}}\right), 2015\left(v_{\mathrm{N} 3}\right), 1616\left(v_{\mathrm{C}=\mathrm{N}}\right), 1468\left(v_{\text {tetrazolate }}\right), 1442\left(v_{\text {tetrazolate }}\right)$. UV-Vis, $\lambda_{\max }(\mathrm{nm}),\left[\varepsilon_{\max }\left(\mathrm{dm}^{3} \mathrm{~mol}^{-1} \mathrm{~cm}^{-1}\right)\right]\left(\mathrm{CH}_{3} \mathrm{CN}\right), 710(3.02$ $\left.\times 10^{2}\right), 352\left(9.85 \times 10^{3}\right), 240\left(5.20 \times 10^{4}\right)$. Magnetic moment: 0.098 BM (diamagnetic).

\section{Crystallographic data collection and refinement}

'Bruker SMART APEX II' diffractometer equipped with graphitemonochromated Mo $\mathrm{K}_{\alpha}$ radiation $(\lambda=0.71073 \AA)$ was used for data collection from suitable single crystals of both complexes. Direct methods were used to solve the molecular structures and full-matrix least squares on $F^{2}$ were used to refine the structures using SHELX-2014 package. ${ }^{21}$ Non-hydrogen atoms were refined with anisotropic thermal parameters. The hydrogen atoms were placed in their geometrically idealized positions and constrained to ride on their parent atoms. Multi-scan empirical absorption corrections were applied to the data using the program SADABS. ${ }^{22}$ Details of the crystallographic data and refinement details of both complexes are given in Table 1.

\section{Details of instrumentation}

Elemental analyses (carbon, hydrogen and nitrogen) were performed using a Perkin Elmer 240C elemental analyzer. IR spectra in $\mathrm{KBr}\left(4500-500 \mathrm{~cm}^{-1}\right)$ were recorded with a Perkin Elmer Spectrum Two spectrophotometer. Electronic spectra in acetonitrile-methanol $(2: 1)$ mixture were recorded on a SHIMADZU UV-1700(E) Pharma Spec UV-Vis spectrophotometer. Steady-state photoluminescence spectra in acetonitrile-methanol (2:1) mixture were obtained with a Shimadzu RF-5301PC spectrofluorometer at room temperature. Time-dependent photoluminescence spectra were recorded using a Hamamatsu MCP photomultiplier (R3809) and were analyzed using IBHDAS6 software. The cyclic voltammetry experiments were performed in DMF solution containing tetrabutylammonium perchlorate (TBAP) as supporting electrolyte using glassy carbon, $\mathrm{Ag} / \mathrm{Ag}+$ (nonaqueous) and platinum wire as working,

Table 1 Crystal data and refinement details of complexes 1 and 2

\begin{tabular}{lll}
\hline & $\mathbf{1}$ & 2 \\
\hline Formula & $\mathrm{C}_{18} \mathrm{H}_{21} \mathrm{CoN}_{10} \mathrm{O}_{2}$ & $\mathrm{C}_{20} \mathrm{H}_{25} \mathrm{CoN}_{10} \mathrm{O}_{2}$ \\
Formula weight & 468.38 & 496.43 \\
Crystal system & Monoclinic & Monoclinic \\
Space group & $P 2_{1} / c$ & $P 2_{1} / c$ \\
$a(\AA)$ & $7.9648(3)$ & $16.1282(4)$ \\
$b(\AA)$ & $7.9932(3)$ & $7.7871(2)$ \\
$c(\AA)$ & $31.0201(11)$ & $18.6891(5)$ \\
$\beta\left({ }^{\circ}\right)$ & $96.409(2)$ & $104.133(1)$ \\
$d\left(\right.$ calc.) $\left[\mathrm{g} \mathrm{cm}^{-3}\right]$ & 1.585 & 1.449 \\
$\mu\left[\mathrm{mm}{ }^{-1}\right]$ & 0.915 & 0.794 \\
$F(000)$ & 968 & 1032 \\
Total reflections & 25838 & 31148 \\
Unique reflections & 3491 & 3995 \\
Observed data $[I>2 \sigma(I)]$ & 3158 & 3493 \\
No. of parameters & 280 & 298 \\
$R$ (int) & 0.04 & 0.031 \\
$R 1$, wR2 (all data) & $0.0607,0.1219$ & $0.0325,0.0745$ \\
$R 1$, w $R 2[I>2 \sigma(I)]$ & $0.0547,0.1194$ & $0.0271,0.0714$ \\
Residual electron density $\left(\mathrm{e} \AA^{-3}\right)$ & $0.683,-0.919$ & $0.199,-0.227$
\end{tabular}




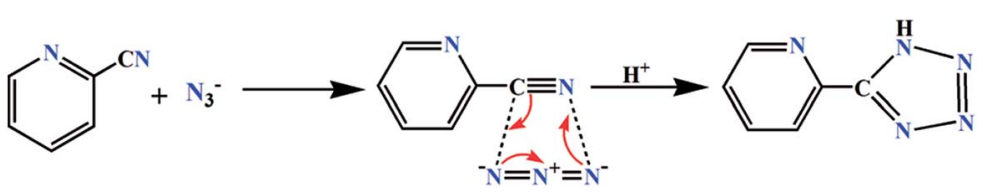

Scheme 1 In situ formation of tetrazolate via 1,3-dipolar cycloaddition reaction.

reference and auxiliary electrodes respectively at ambient temperature $(300 \mathrm{~K})$ with no trace of decomposition as reflected in the smooth curve, in the potential range from -2 to $+2 \mathrm{~V}$ and were uncorrected for junction contribution. The magnetic susceptibility measurements were done with an EG \& PAR vibrating sample magnetometer, model 155 at room temperature and diamagnetic corrections were made using Pascal's constants. X-ray diffraction of the powder samples were performed on a Bruker D8 instrument with $\mathrm{Cu} \mathrm{K}_{\alpha}$ radiation $(\lambda=$ $1.54184 \AA$ A). Electrospray ionization mass spectra were recorded using Waters QTOF Micro YA263 mass analyzer. Electron paramagnetic resonance (EPR) spectra were recorded in standard quartz EPR tubes using JEOL JES-FA200 X-band spectrometer.

\section{Hirshfeld Surface analysis}

Hirshfeld surfaces ${ }^{23}$ and the fingerprint ${ }^{24}$ (2D) plots were calculated using Crystal Explorer. ${ }^{25}$ The details could be found in many previous papers. ${ }^{26,27}$

\section{Theoretical methods}

The calculations of the noncovalent interactions were carried out using the TURBOMOLE version 7.0 (ref. 28) using the BP86D3/def2-TZVP level of theory. To evaluate the interactions in the solid state, the crystallographic coordinates were used. This procedure and level of theory was successfully used to evaluate similar interactions. ${ }^{29}$ The interaction energies were computed by calculating the difference between the energies of isolated monomers and their assembly. The interaction energies were corrected for the Basis Set Superposition Error (BSSE) using the counterpoise method. ${ }^{30}$ The molecular electrostatic potential surfaces were computed using the SPARTAN software. ${ }^{31}$ The Bader's "atoms-in-molecules" analysis was performed at the same level of theory, using the AIMAll program. ${ }^{32}$

\section{Kinetics of the catalytic oxidations of 3,5-DTBC and $o$ - aminophenol}

With the aim of study the catechol oxidase and phenoxazinone synthase mimicking activity of cobalt(III) tetrazolato complexes, $10^{-4} \mathrm{M}$ solution of each complex in acetonitrile-methanol $(2: 1)$ mixture was treated with at least ten equivalents of substrate solution separately (3,5-DTBC for catechol oxidase mimicking activity and $o$-aminophenol for phenoxazinone synthase mimicking activity) under aerobic conditions at room temperature. All catalytic reactions were monitored spectrophotometrically for $\sim 2 \mathrm{~h}$ in the wavelength range $300-500 \mathrm{~nm}$. In the catalytic oxidations of 3,5-DTBC and $o$-aminophenol the increase in the absorbance as a function of time around 401 and $433 \mathrm{~nm}$ respectively, confirms the formation of corresponding chromophores. In addition, to check the rate dependency on catalyst concentration, similar sets of experiments were performed at a fixed concentration of substrate with variable

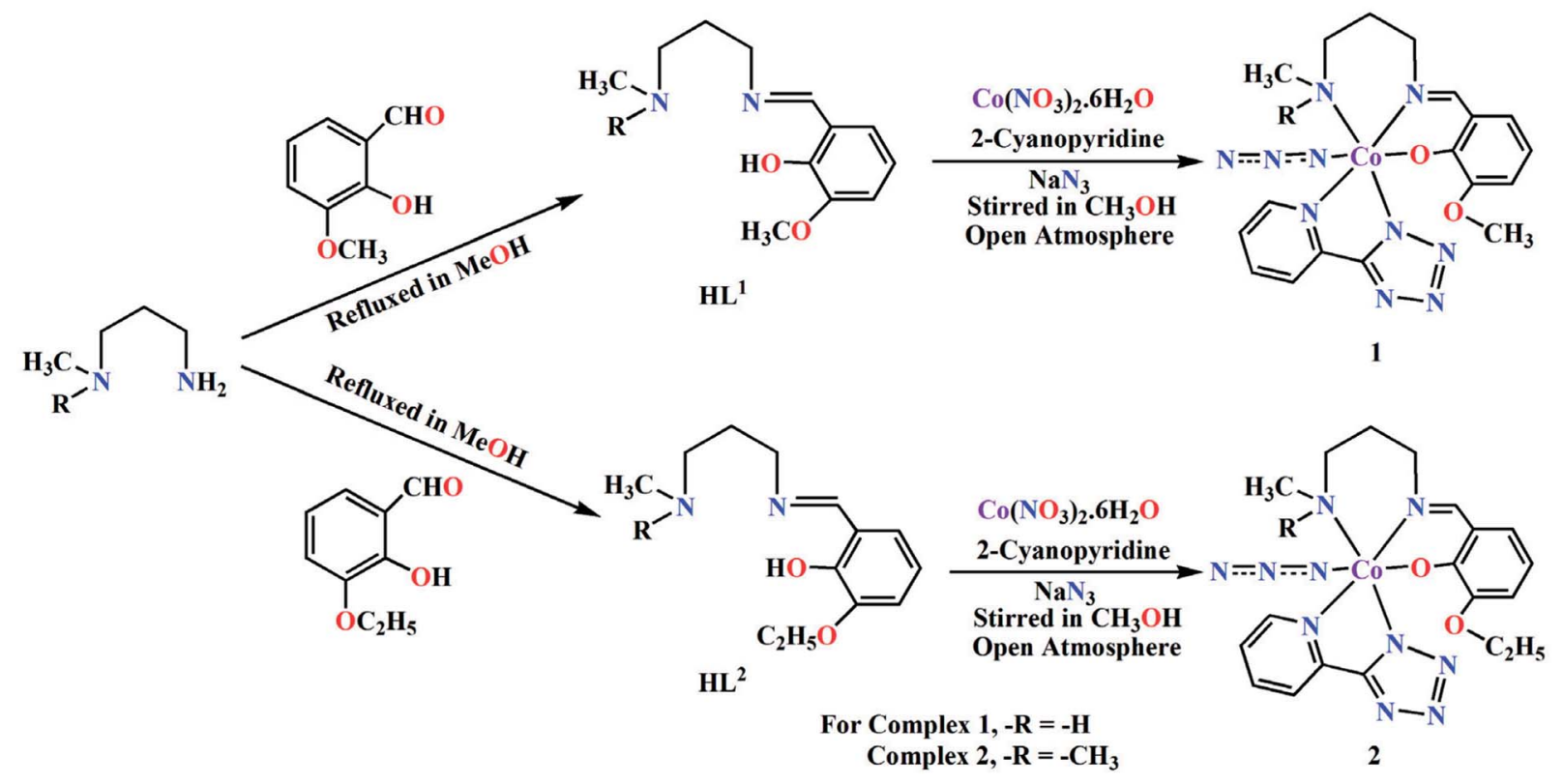

Scheme 2 Synthetic route to complexes 1 and 2 . 


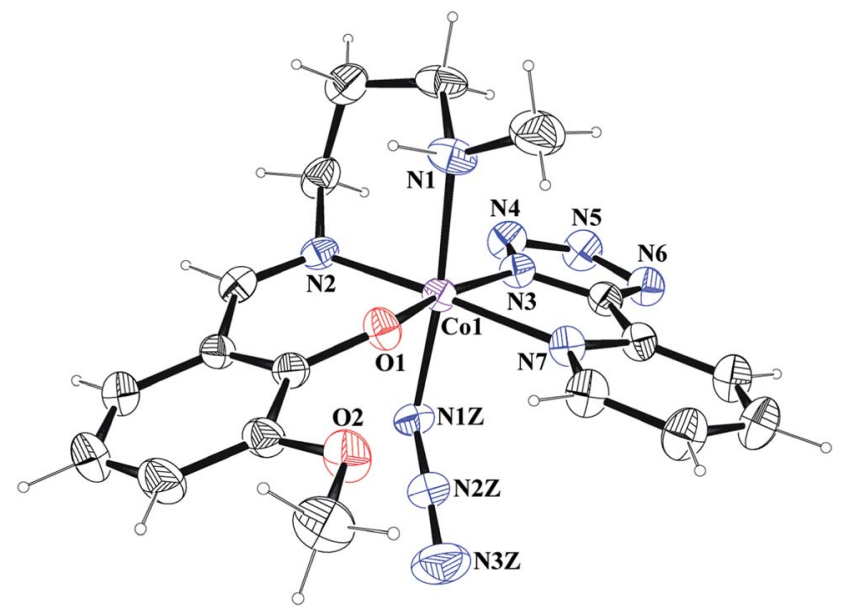

Fig. 1 ORTEP presentation of complex 1 (ellipsoids are drawn at the $40 \%$ probability level) with selected atom-numbering scheme.

amounts of catalyst concentrations. Rate of the reactions was derived from the initial rate method, and the average initial rate over three independent measurements was recorded.

\section{Results and discussion}

\section{Synthesis}

In current investigation, two Schiff base ligands $\mathrm{HL}^{1}$ and $\mathrm{HL}^{2}$ were used as blocking ligands to prepare two mononuclear cobalt(III) tetrazolato complexes. $\mathrm{HL}^{1}$ was synthesized by the $1: 1$ condensation of $\mathrm{N}$-methyl-1,3-diaminopropane with the 3methoxysalicylaldehyde whereas, $\mathrm{HL}^{2}$ was synthesized by similar $1: 1$ condensation of $\mathrm{N}, \mathrm{N}$-dimethyl-1,3-propanediamine with 3-ethoxysalicylaldehyde in methanol following the literature method. ${ }^{33}$ The ligands were not isolated and the yellow coloured methanol solutions were used directly for the synthesis of cobalt(III) complexes. On the other hand, the

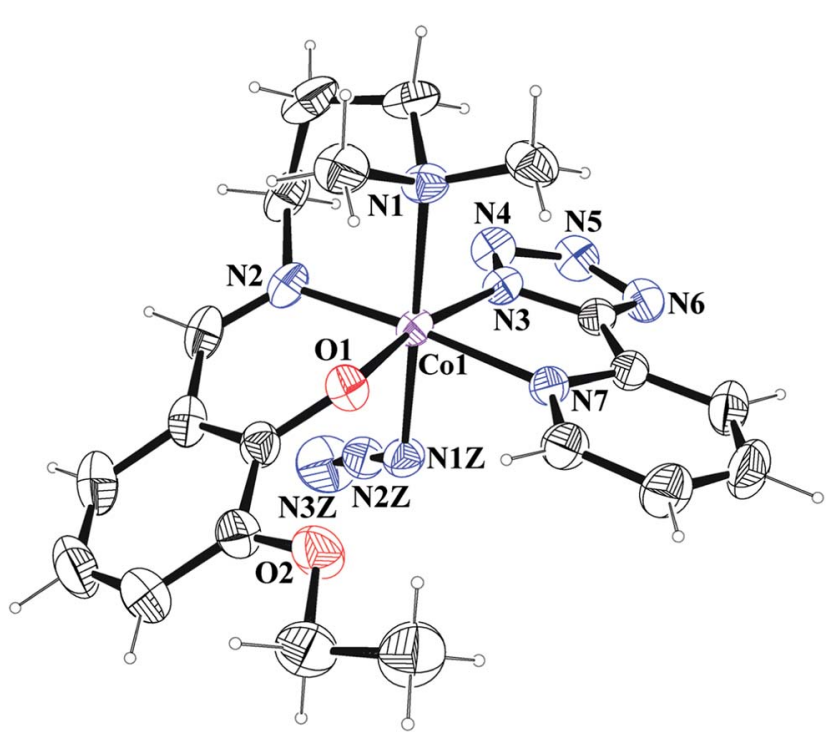

Fig. 2 ORTEP presentation of complex 2 (ellipsoids are drawn at the $40 \%$ probability level) with selected atom-numbering scheme.
Table 2 Selected bond lengths $(\AA)$ of complexes 1 and 2

\begin{tabular}{lll}
\hline & 1 & 2 \\
\hline $\mathrm{Co}(1)-\mathrm{O}(1)$ & $1.871(2)$ & $1.8651(14)$ \\
$\mathrm{Co}(1)-\mathrm{N}(1)$ & $2.002(3)$ & $2.0720(15)$ \\
$\mathrm{Co}(1)-\mathrm{N}(1 \mathrm{Z})$ & $1.952(3)$ & $1.9521(16)$ \\
$\mathrm{Co}(1)-\mathrm{N}(2)$ & $1.911(3)$ & $1.9076(17)$ \\
$\mathrm{Co}(1)-\mathrm{N}(3)$ & $1.955(3)$ & $1.9419(15)$ \\
$\mathrm{Co}(1)-\mathrm{N}(7)$ & $1.981(3)$ & $1.9911(15)$ \\
\hline
\end{tabular}

tetrazolate was prepared in situ by 1,3-dipolar cycloaddition of 2cyanopyridine and azide (Scheme 1$)^{34}$

The complexes were prepared in situ by the reaction of cobalt(II) nitrate hexahydrate, 2-cyanopyridine and sodium azide with the corresponding Schiff base ligands $\left(\mathrm{HL}^{1}\right.$ for 1 and $\mathrm{HL}^{2}$ for 2) under stirring condition using methanol as solvent. Cobalt(II) is readily oxidised to cobalt(III) by aerial oxygen in presence of strong field Schiff base ligands, as was also observed in similar complexes. ${ }^{35}$ Cobalt(II) is quite stable in aqueous (or methanol) medium and remains as high spin $\operatorname{Co}(\mathrm{L})_{6}{ }^{2+}(\mathrm{L}=$ $\mathrm{H}_{2} \mathrm{O}, \mathrm{CH}_{3} \mathrm{OH}$ ), which assumes a pale pink colour. The electronic configuration of this species is $t_{2 g}^{5} \mathrm{e}_{\mathrm{g}}^{2}$. On adding a strong field ligand, the spin state changes to LS with concomitant change in the electronic configuration to $t_{2 g}^{6} \mathrm{e}_{\mathrm{g}}^{1}$. If the strong field ligand produces sufficient strong field, $10 \mathrm{Dq}$ becomes very high. This leads to severe destabilization of the $e_{g}$ electron, which, in turn, is responsible for the easy removal of this electron, leading to the oxidation of cobalt(II) to cobalt(III).

We have repeated the reaction under $\mathrm{N}_{2}$ atmosphere, but no complex could be isolated. The formation of both complexes is shown in Scheme 2.

\section{Description of crystal structures}

$\left[\operatorname{Co}\left(L^{1}\right)(P T Z)\left(N_{3}\right)\right] \quad(1)$ and $\left[\operatorname{Co}\left(L^{2}\right)(P T Z)\left(N_{3}\right)\right]$ (2). Both complexes crystallize in the monoclinic space group $P 2_{1} / c$. The structures consist of discrete mononuclear units in each of which cobalt(III) exhibits similar coordination environment. The perspective views of complexes $\mathbf{1}$ and $\mathbf{2}$ together with

Table 3 Selected bond angles $\left({ }^{\circ}\right)$ of complexes 1 and 2

\begin{tabular}{lll}
\hline & 1 & 2 \\
\hline $\mathrm{O}(1)-\mathrm{Co}(1)-\mathrm{N}(1)$ & $86.56(12)$ & $90.60(6)$ \\
$\mathrm{O}(1)-\mathrm{Co}(1)-\mathrm{N}(1 \mathrm{Z})$ & $93.19(12)$ & $89.33(6)$ \\
$\mathrm{O}(1)-\mathrm{Co}(1)-\mathrm{N}(2)$ & $92.00(12)$ & $91.15(6)$ \\
$\mathrm{O}(1)-\mathrm{Co}(1)-\mathrm{N}(3)$ & $168.01(12)$ & $168.59(6)$ \\
$\mathrm{O}(1)-\mathrm{Co}(1)-\mathrm{N}(7)$ & $87.57(12)$ & $87.67(6)$ \\
$\mathrm{N}(1)-\mathrm{Co}(1)-\mathrm{N}(1 \mathrm{Z})$ & $173.85(14)$ & $179.27(7)$ \\
$\mathrm{N}(1)-\mathrm{Co}(1)-\mathrm{N}(2)$ & $85.18(14)$ & $88.19(7)$ \\
$\mathrm{N}(1)-\mathrm{Co}(1)-\mathrm{N}(3)$ & $93.94(13)$ & $92.72(6)$ \\
$\mathrm{N}(1)-\mathrm{Co}(1)-\mathrm{N}(7)$ & $97.44(13)$ & $96.19(6)$ \\
$\mathrm{N}(1 \mathrm{Z})-\mathrm{Co}(1)-\mathrm{N}(2)$ & $88.69(13)$ & $91.08(7)$ \\
$\mathrm{N}(1 \mathrm{Z})-\mathrm{Co}(1)-\mathrm{N}(3)$ & $87.58(13)$ & $87.48(6)$ \\
$\mathrm{N}(1 \mathrm{Z})-\mathrm{Co}(1)-\mathrm{N}(7)$ & $88.69(13)$ & $84.53(6)$ \\
$\mathrm{N}(2)-\mathrm{Co}(1)-\mathrm{N}(3)$ & $99.98(13)$ & $99.85(7)$ \\
$\mathrm{N}(2)-\mathrm{Co}(1)-\mathrm{N}(7)$ & $177.31(14)$ & $175.47(7)$ \\
$\mathrm{N}(3)-\mathrm{Co}(1)-\mathrm{N}(7)$ & $80.48(13)$ & $81.12(6)$
\end{tabular}


(a)

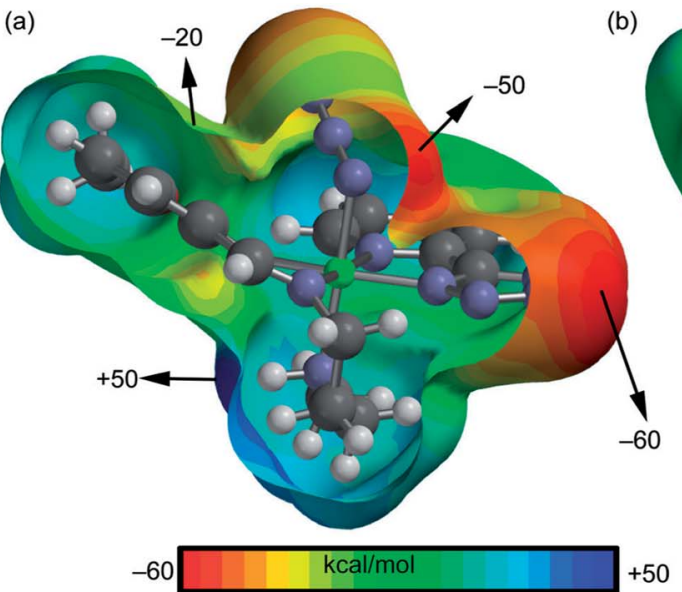

(b)

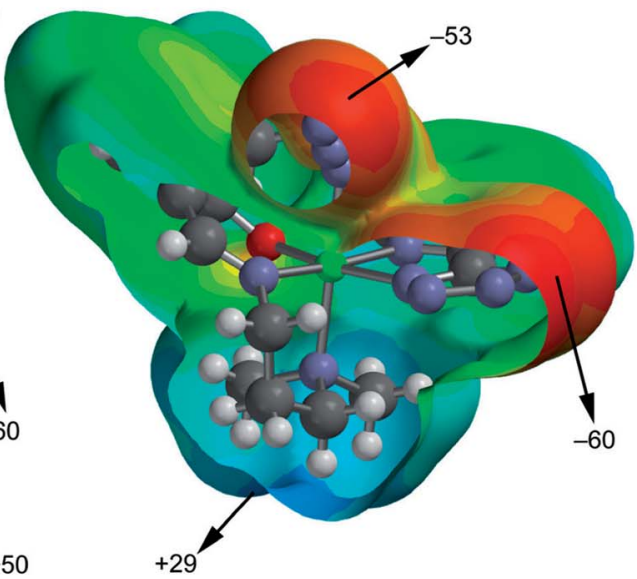

Fig. 3 MEP surfaces of complexes 1 (a) and 2 (b) with indication of the energetic values in selected point of the surface (isosurface at 0.002 a.u.).

selected atom-numbering schemes are shown in Fig. 1 and 2 respectively. In each complex, cobalt(III) is in a distorted octahedral environment being coordinated by the phenoxo oxygen atom, $\mathrm{O}(1)$, the amine nitrogen atom, $\mathrm{N}(1)$, and the imine nitrogen atom, N(2), from the deprotonated Schiff base ligand $\left\{\left(\mathrm{L}^{1}\right)^{-}\right.$for complex $\mathbf{1}$ and $\left(\mathrm{L}^{2}\right)^{-}$for complex $\left.\mathbf{2}\right\}$ and two additional nitrogen atoms, $\mathrm{N}(3)$ and $\mathrm{N}(7)$, from 2-pyridyltetrazolate, (PTZ) ${ }^{-}$ in the equatorial plane and by the amine nitrogen atom, $\mathrm{N}(1)$ of the tridentate Schiff base and another nitrogen atom, $\mathrm{N}(1 \mathrm{Z})$ of a terminal azide in the axial positions. It is to be noticed here that in each case, the Schiff base is occupying one facial position. Thus the important point may be the bending of the Schiff base. In the equatorial plane, pyridyltetrazolate and Schiff base moieties are not co-planar, but they form dihedral angles of $32.65^{\circ}$ (in 1) and $43.19^{\circ}$ (in 2). Azide moieties are differently oriented in the coordination sphere of the two complexes that lead to different packing patterns in their solid state structures. The bond lengths and bond angles of the complexes (given in

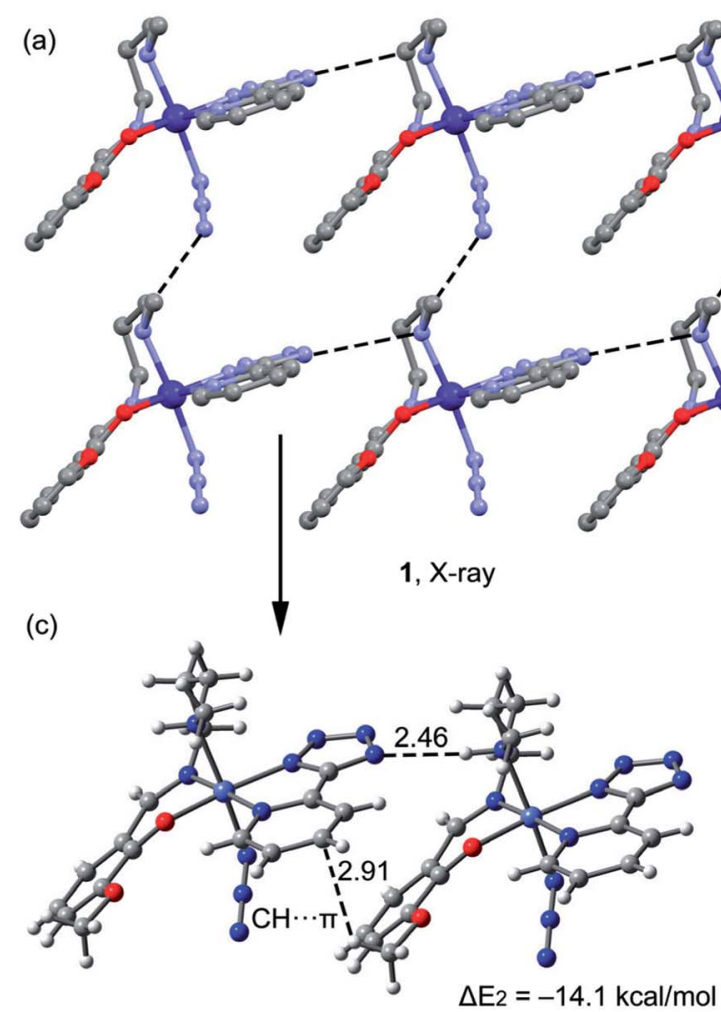

(b)
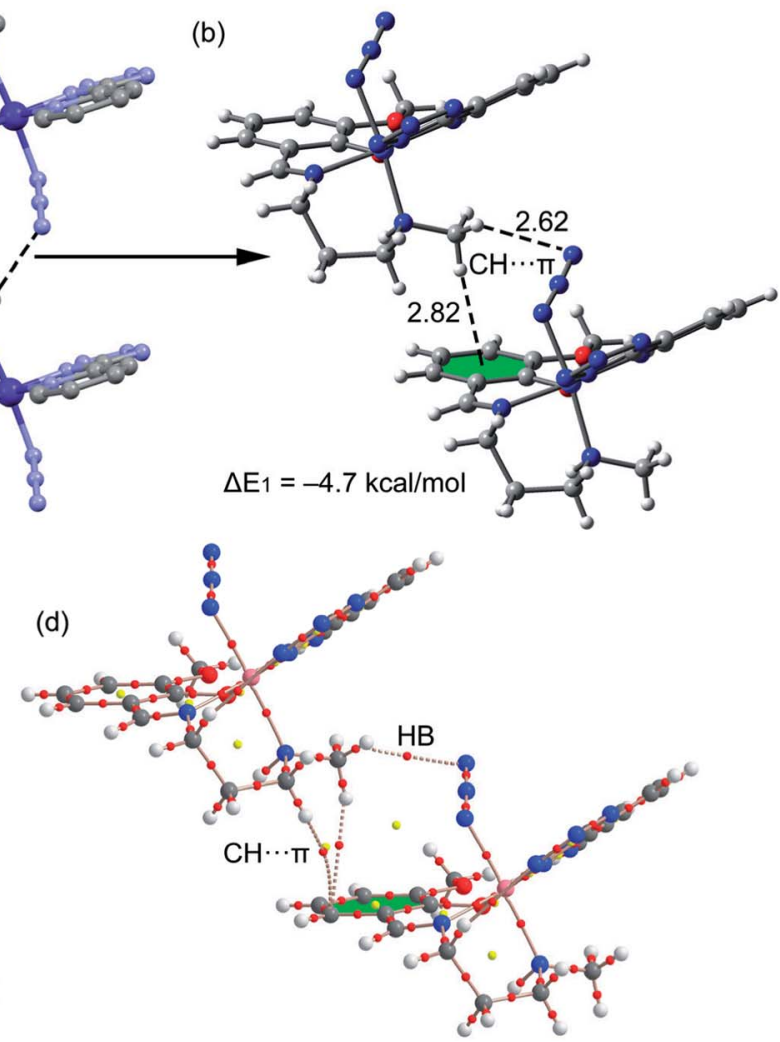

Fig. 4 (a) Crystal packing of 1 (hydrogen atoms omitted); ( $b$ and c) theoretical models used to evaluate the noncovalent interactions (distances in A); (d) distribution of bond and ring (red and yellow spheres) critical points in one dimer of complex 1 . 
(a)
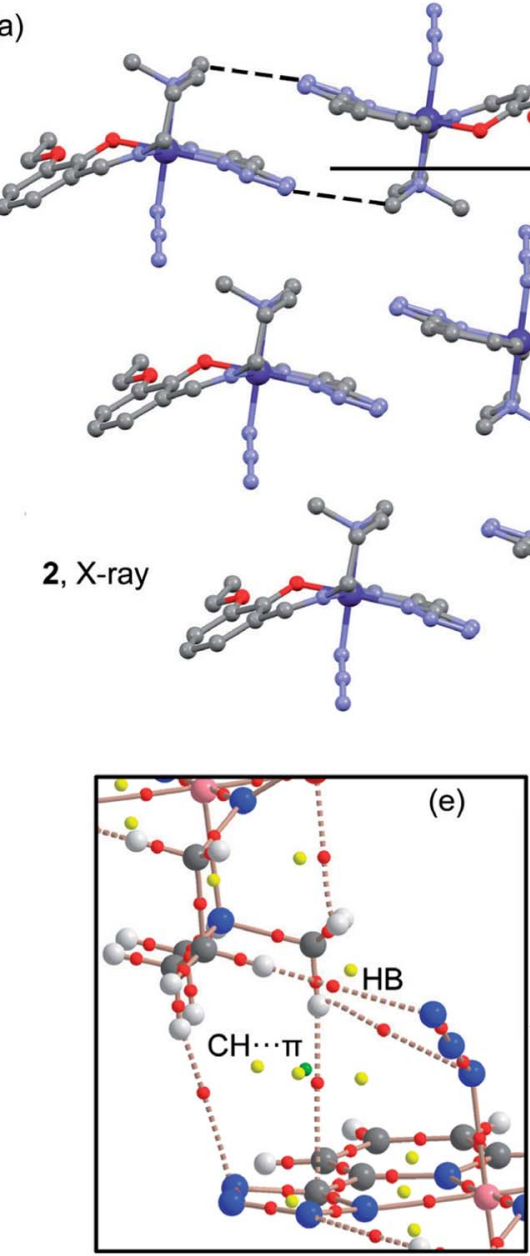

(b)
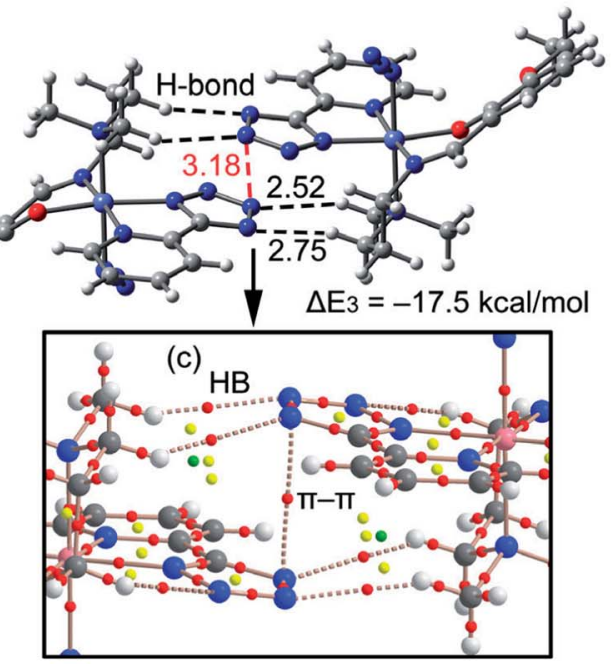

(d)
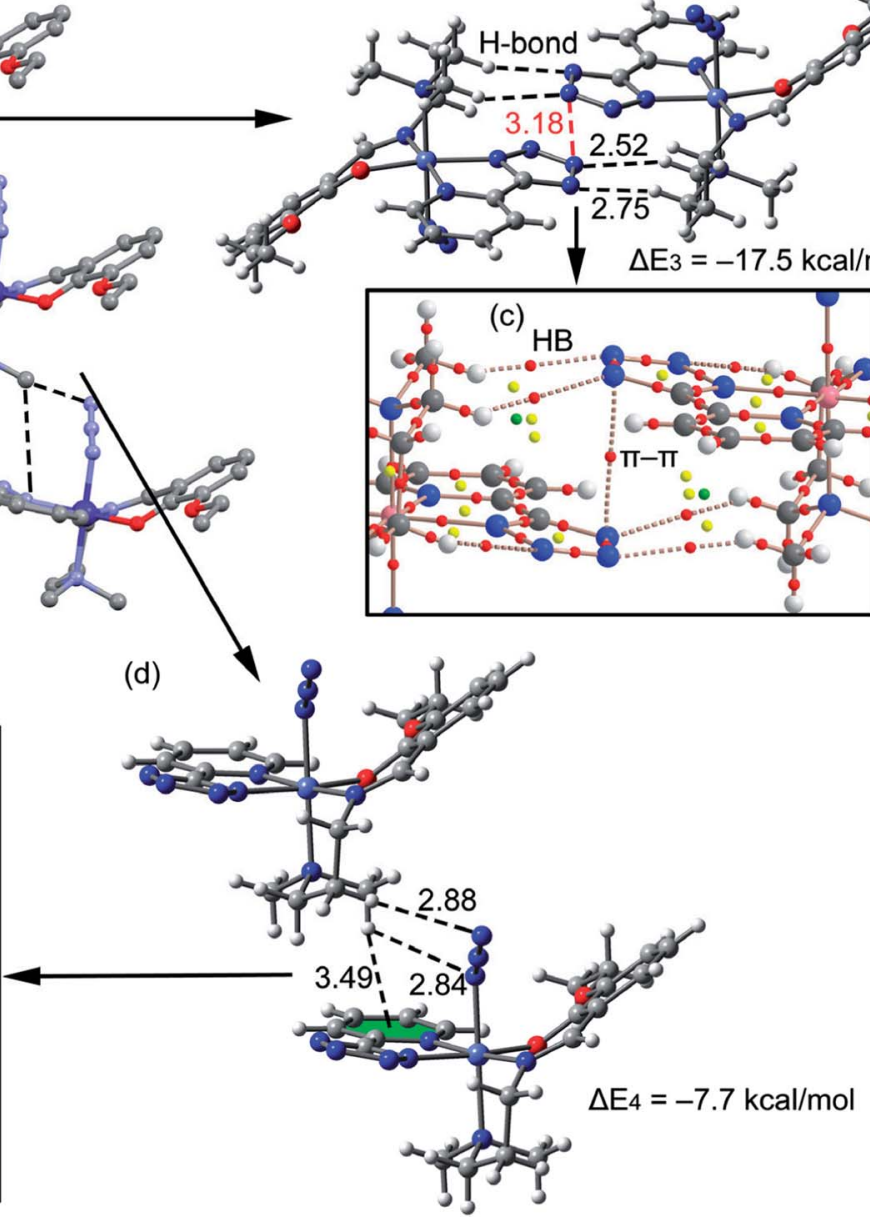

Fig. 5 (a) Crystal packing of 2 (hydrogen atoms omitted); ( $b$ and c) theoretical models used to evaluate the noncovalent interactions (distances in A); ( $d$ and e) distribution (partial views) of bond, ring and cage (red, yellow and green spheres) critical points in two dimers of complex 2.
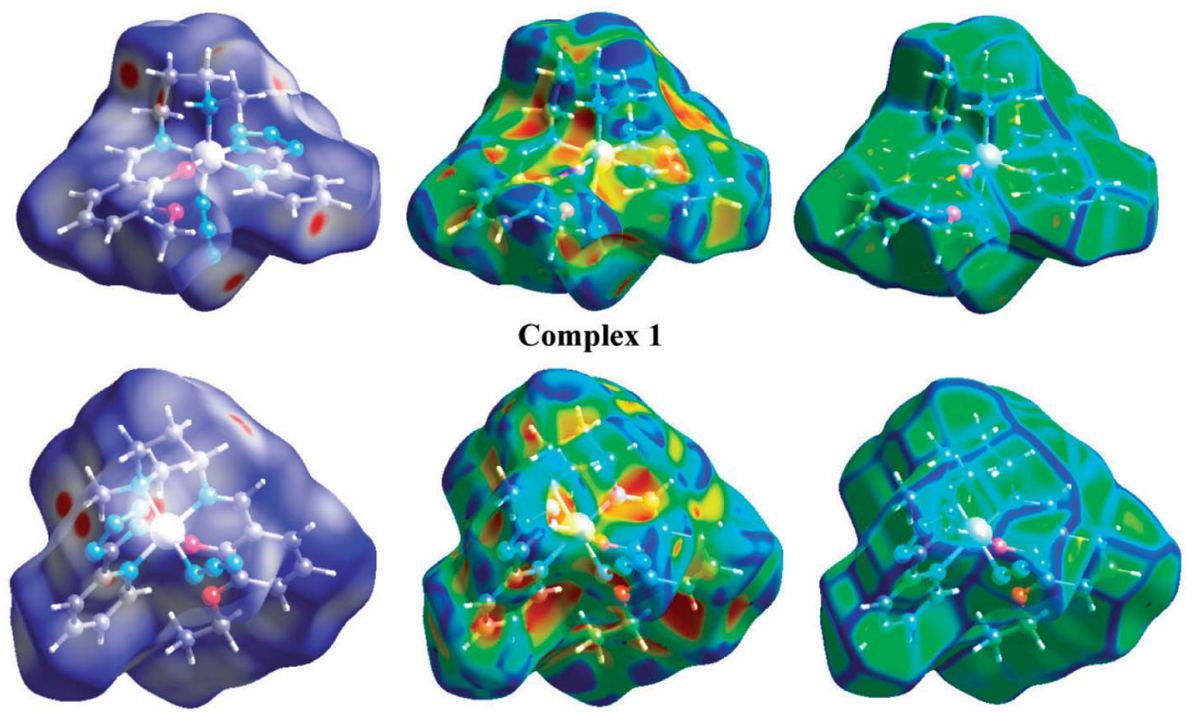

Complex 2

Fig. 6 Hirshfeld surfaces mapped with $d_{\text {norm }}$ (left-side), shape index (middle) and curvedness (right-side). 


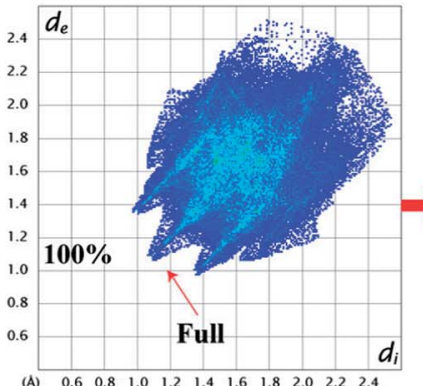

(A) \begin{tabular}{llllllllllll}
0.6 & 0.8 & 1.0 & 1.2 & 1.4 & 1.6 & 1.8 & 2.0 & 2.2 & 2.4 \\
\hline$d_{e}$ & & & & & & & & & &
\end{tabular}



${ }_{2.0} d_{e}=1.04$

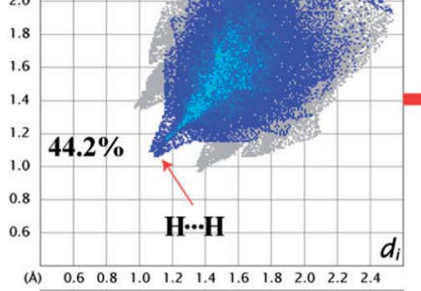

${ }_{2.4}^{\text {(A) }} d_{e}$

$2.4 \frac{d_{e}}{d_{i}=1.03}$

$2.2 \quad d_{i}=1.03$

\begin{tabular}{l|l}
2.0 & $\mathrm{H} \cdots \mathrm{C}$ \\
1.8 & $\mathrm{~g}^{2}$
\end{tabular}
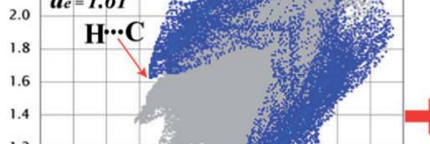

1.2

\begin{tabular}{l|l|}
1.2 & $\mathbf{1 1 . 6} \%$ \\
\hline &
\end{tabular}

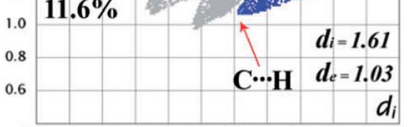

(A) $\begin{array}{llllllllllll}0.6 & 0.8 & 1.0 & 1.2 & 1.4 & 1.6 & 1.8 & 2.0 & 2.2 & 2.4\end{array}$

$2.4 d_{e}$

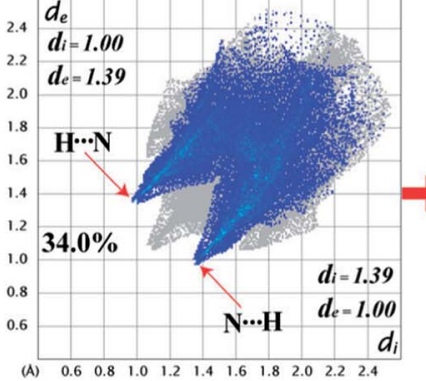

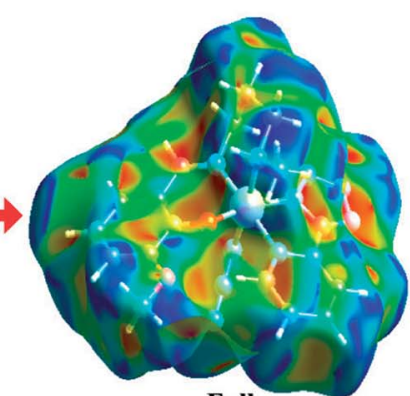

Full



$\mathbf{H} \cdots \mathbf{H}$

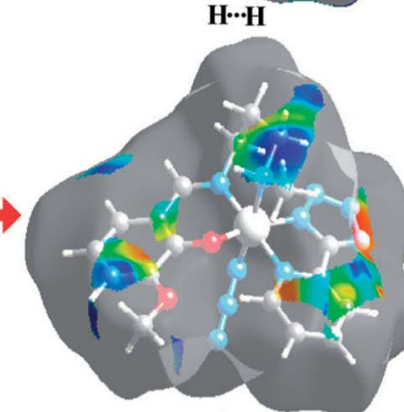

$\mathbf{C} \cdot \mathbf{H} / \mathbf{H} \cdots \mathbf{C}$

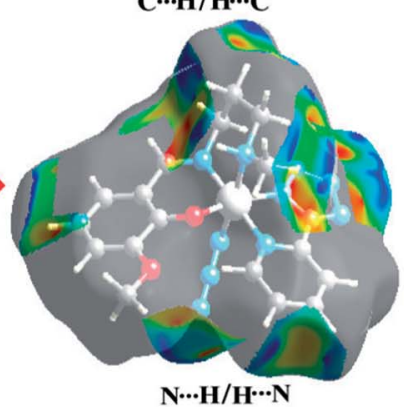

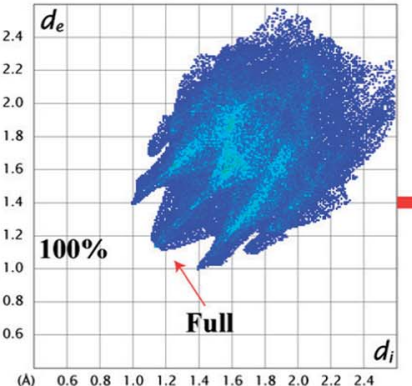
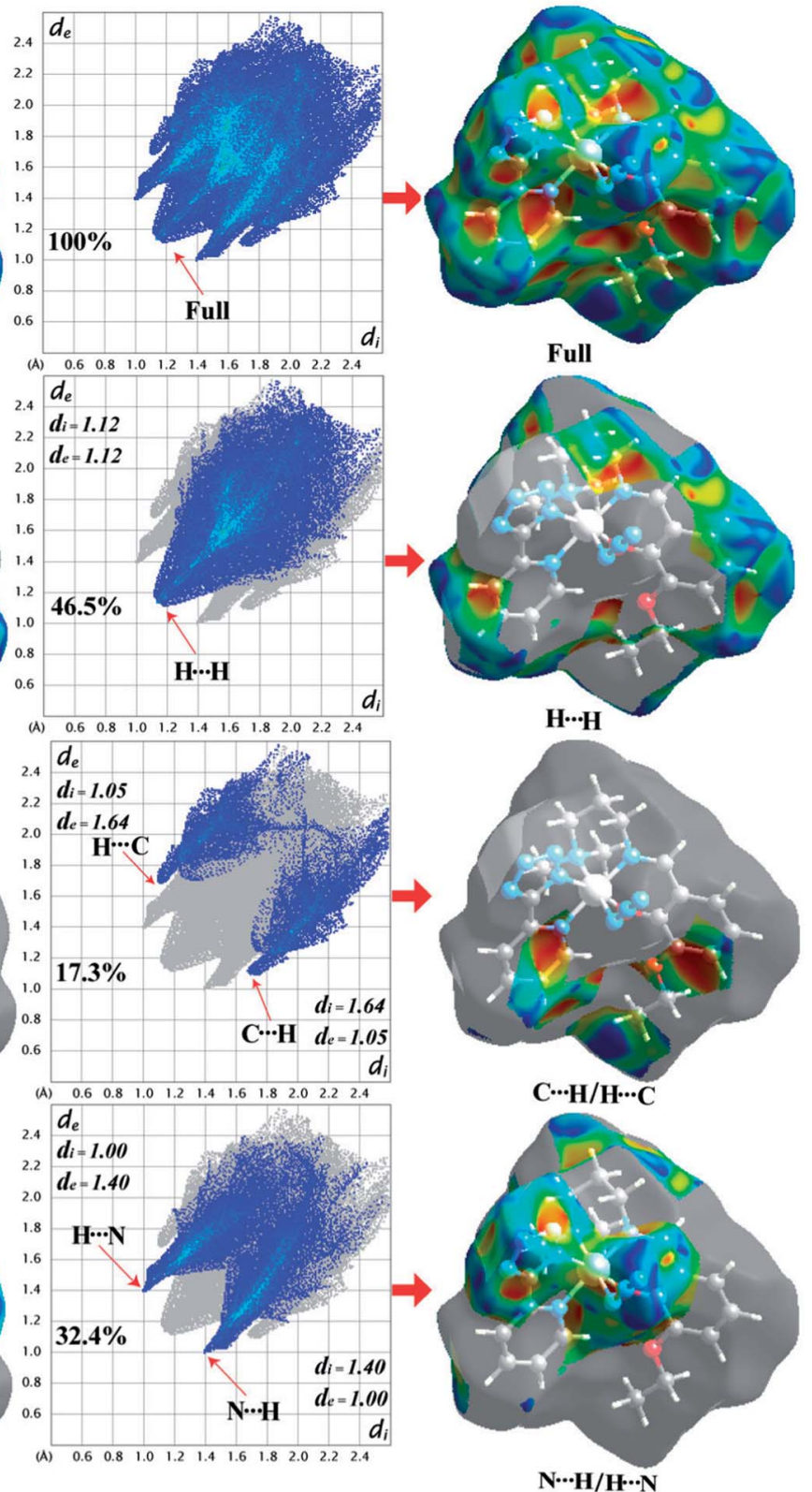

Fig. 7 Fingerprint plots of 1 (left-side) and 2 (right-side): full and resolved into $\mathrm{H} \cdots \mathrm{H}, \mathrm{C} \cdots \mathrm{H} / \mathrm{H} \cdots \mathrm{C}, \mathrm{N} \cdots \mathrm{H} / \mathrm{H} \cdots \mathrm{N}$ contacts showing the percentages of contacts contributed to the total Hirshfeld surface area of both complexes. Surfaces in the right hand columns highlight the relevant surface patches associated with the specific contacts in the total Hirshfeld surface area of complexes 1 and 2

Table 4 The details data of the photoluminescence and timeresolved photoluminescence decays of complexes 1 and 2

\begin{tabular}{lllll}
\hline Complexes & $\begin{array}{l}\text { Absorption } \\
(\mathrm{nm})\end{array}$ & $\begin{array}{l}\text { Emission } \\
(\mathrm{nm})\end{array}$ & $\begin{array}{l}\text { Time } \\
(\mathrm{ns})\end{array}$ & $\chi^{2}$ \\
\hline $\mathbf{1}$ & 240 & 350 & 7.24 & 1.042081 \\
2 & 240 & 380 & 7.91 & 1.067222
\end{tabular}

Tables 2 and 3, respectively) are comparable with previously reported octahedral cobalt(III) Schiff base complexes. ${ }^{\mathbf{2 0 c}, 34}$ The distortion of the octahedral geometry can be easily observed from the bond angles, which deviate from the ideal values of $90^{\circ}$ (for the cis angles) or $180^{\circ}$ (for the trans angles). The Co(III)$\mathrm{N}_{\text {imine }}$ distances are shorter than the $\mathrm{Co}$ (III) $-\mathrm{N}_{\text {amine }}$ ones, due to the different hybridization of nitrogen atoms. This is a common phenomenon observed in many other cobalt(III) Schiff base complexes. ${ }^{36}$ The saturated six member chelate rings, $\mathrm{Co}(1)-$ $\mathrm{N}(1)-\mathrm{C}(2)-\mathrm{C}(3)-\mathrm{C}(4)-\mathrm{N}(2)$ (for complex 1) and $\mathrm{Co}(1)-\mathrm{N}(1)-\mathrm{C}(3)-$ $\mathrm{C}(4)-\mathrm{C}(5)-\mathrm{N}(2)$ (for complex 2) are present in chair conformations with puckering parameters ${ }^{37 a} q=0.674(3) \AA, \theta=13.3(3), \phi$ $=352.2(15)^{\circ}$ (for complex 1) and $q=0.6724(18) \AA, \theta=12.55(17)$, $\phi=4.8(8)^{\circ}$ (for complex 2). 


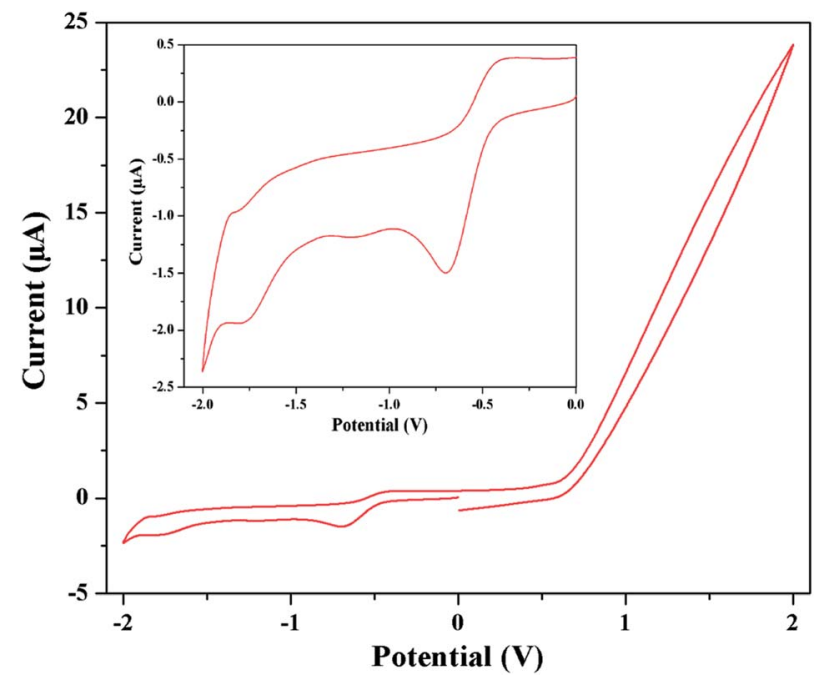

Fig. 8 Cyclic voltammogram of complex 1 in DMF medium. Inset shows the voltammogram in between -2 to $0 \mathrm{~V}$.

\section{Theoretical study of noncovalent interactions}

We have focused our attention to the study of relevant hydrogen bonding and $\mathrm{C}-\mathrm{H} \cdots \pi$ interactions observed in the solid state architecture of both complexes. At first, the MEP surfaces of both complexes were computed to investigate the most positive and negative regions in order to rationalize the interactions observed in their crystal packing. The MEP surfaces are given in Fig. 3 and it can be observed that the most negative region is located at the nitrogen atoms of the tetrazole ring in both complexes $\left(-60 \mathrm{kcal} \mathrm{mol}^{-1}\right)$ and the most positive one at the $\mathrm{NH}$ group in complex $1\left(+50 \mathrm{kcal} \mathrm{mol}^{-1}\right)$ and at the hydrogen atoms of the coordinated $\mathrm{N}\left(\mathrm{CH}_{3}\right)_{2}$ group in $2\left(+29 \mathrm{kcal} \mathrm{mol}^{-1}\right)$. The nitrogen atoms of the azide are also present in strongly negative MEP values. Therefore interactions involving the $\mathrm{NH}$ / $\mathrm{N}\left(\mathrm{CH}_{3}\right)_{2}$ groups as hydrogen bond donors and tetrazole/azide as acceptors are electrostatically favored.

A fragment of the crystal packing of complex $\mathbf{1}$ is shown in Fig. $4 \mathrm{a}$, where the formation of 2D layer is highlighted. In one direction the chain is governed by hydrogen bonding interactions (Fig. 4c) and in the perpendicular direction the molecules interact by means of $\mathrm{C}-\mathrm{H} \cdots \pi$ interactions (Fig. $4 \mathrm{~b}$ ). The interaction energies of both assemblies were evaluated using the models shown in Fig. 4c. It can be easily observed that the hydrogen bonding dimer is energetically more favorable $\left(\Delta E_{2}=\right.$ $\left.-14.1 \mathrm{kcal} \mathrm{mol}^{-1}\right)$ than the dimer $\left(\Delta E_{1}=-4.7 \mathrm{kcal} \mathrm{mol}^{-1}\right)$ governed by $\mathrm{CH} \cdots \pi$ interactions. In the latter, two different $\pi$ systems are involved, the conventional aromatic ring (at $2.82 \AA$ to the ring centroid) and the $\pi$-system of the azide, since the directionality of the interaction (hydrogen bond) indicates that the hydrogen atom is pointing to the $\pi$ instead of the $\sigma$-electrons of the pseudohalide. The hydrogen bonded dimer presents stronger interaction energy in agreement to the MEP surface, since the interaction of $\mathrm{N}-\mathrm{H}$ and tetrazole is very favored electrostatically. The $\mathrm{C}-\mathrm{H} \cdots \pi$ interaction described in Fig. 4c (2.91 $\AA$ to one $\mathrm{C}$ atom of the ring) is similar to that previously highlighted by N. Nishio in the crystal structure of levopimaric acid (2.94 $\AA$ to one carbon atom) $)^{37 b}$ and also in phenyl-substituted tetrahydroisoquinoline derivatives (2.86 A). ${ }^{37 c}$ Similar $\mathrm{C}-\mathrm{H} \cdots \pi$ interactions have also been commonly described in supramolecular assemblies of several complexes, reported in previous journals. ${ }^{37 d, e}$ The Bader's theory of atomsin-molecules was used to further confirm the existence of the $\mathrm{CH} \cdots \pi$ interactions. The existence of a bond critical point (CP) and bond path connecting two atoms is an unambiguous evidence of interaction. The distributions of critical points and bond paths for the dimer of complex 1 are shown in Fig. 4 d. It can be observed that the conventional $\mathrm{C}-\mathrm{H} \cdots \pi$ (phe) interaction is characterized by the presence of two bond CPs (red spheres) and bond paths connecting two hydrogen atoms to the phenyl ring. Moreover, the unconventional $\mathrm{C}-\mathrm{H} \cdots \pi$ (azide) interaction is characterized by the presence of a bond CP and bond path connecting the hydrogen atom to a nitrogen atom of the ligand, thus confirming the existence of the interaction.

A fragment of the crystal packing of complex 2 is shown in Fig. 5a, where the formation of $2 \mathrm{D}$ layers is highlighted. Complex 2 forms self-assembled dimers governed by hydrogen bonding and $\pi-\pi$ stacking interactions (see black and red dashed lines, respectively, Fig. 5b). This self-assembled dimer interacts with the adjacent one by means of $\mathrm{C}-\mathrm{H} \cdots \pi$ interactions (see Fig. $5 \mathrm{~d}$ ) involving the $\pi$-systems of phenyl and azide moieties, as previously observed in complex $\mathbf{1}$. The interaction energies of both assemblies were evaluated using the models shown in Fig. 5b and d. It can be observed that the selfassembled hydrogen bonding dimer is energetically very favorable $\left(\Delta E_{3}=-17.5 \mathrm{kcal} \mathrm{mol}^{-1}\right)$ due to the formation of several hydrogen bonds. The interaction energy of the other dimer governed by $\mathrm{C}-\mathrm{H} \cdots \pi$ interactions is more modest $\left(\Delta E_{4}=\right.$ $-7.7 \mathrm{kcal} \mathrm{mol}^{-1}$ ). In complex 2 the conventional aromatic ring involved in the $\mathrm{C}-\mathrm{H} \cdots \pi$ (phe) interaction belongs to the PTZ ligand instead to the Schiff-base ligand. In addition, two $\mathrm{H}$ atoms of the $\mathrm{N}\left(\mathrm{CH}_{3}\right)_{2}$ group interact with $\pi$-system of the azide $(2.8 \AA)$. The distributions of critical points and bond paths for the dimers of 2 are shown in Fig. $5 c$ and e. In the selfassembled dimer, it can be observed that each hydrogen bonding interaction is characterized by the presence of one bond CPs (red spheres) and bond path that connects the hydrogen atom to the nitrogen atom of the tetrazole ring

Table 5 Cyclic voltammetry data (V) for both complexes in DMF medium (scan rate $25 \mathrm{mV} \mathrm{s}^{-1}$ )

\begin{tabular}{|c|c|c|c|c|c|c|c|c|}
\hline Complexes & $E_{\mathrm{III} \rightarrow \mathrm{II}}$ & $E_{\mathrm{II} \rightarrow \mathrm{III}}$ & $\Delta E_{\mathrm{III} \leftrightarrow \mathrm{II}}$ & $\begin{array}{l}E_{1 / 2} \\
\mathrm{III} \leftrightarrow \mathrm{II}\end{array}$ & $E_{\mathrm{II} \rightarrow \mathrm{I}}$ & $E_{\mathrm{I} \rightarrow \mathrm{II}}$ & $\Delta E_{\mathrm{II} \leftrightarrow \mathrm{I}}$ & $E_{1 / 2} \mathrm{II} \leftrightarrow \mathrm{I}$ \\
\hline 1 & -0.70 & -0.38 & 0.32 & -0.54 & -1.80 & -1.84 & 0.04 & -1.82 \\
\hline
\end{tabular}


(Fig. 5c). The interaction is further characterized by the presence of a ring CP (yellow sphere) due to the formation of a supramolecular ring. Moreover, the $\pi \cdots \pi$ interaction is characterized by the presence of a bond CP and bond path interconnecting two nitrogen atoms of the tetrazole rings, thus confirming the existence of the interaction. Finally, in Fig. 5e it is shown the distribution of CPs for the $\mathrm{C}-\mathrm{H} \cdots \pi$ assembly. It can be observed that the conventional $\mathrm{C}-\mathrm{H} \cdots \pi$ (phe) interaction is characterized by the presence of two bond CPs (red spheres) and bond paths connecting two hydrogen atoms of the methyl groups to the phenyl ring and tetrazole rings. Moreover, the unconventional $\mathrm{C}-\mathrm{H} \cdots \pi$ (azide) interaction is characterized by the presence of two bond CPs and bond paths connecting two hydrogen atoms of the $\mathrm{N}\left(\mathrm{CH}_{3}\right)_{2}$ group to two $\mathrm{N}$-atoms of the pseudohalide.

\section{Hirshfeld surface analysis}

The Hirshfeld surfaces of the two complexes, mapped over $d_{\text {norm }}$ (range of -0.1 to $1.5 \AA$ ), shape index and curvedness, are illustrated in Fig. 6. The dominant interaction between $\mathrm{N} \cdots \mathrm{H} /$ $\mathrm{H} \cdots \mathrm{N}$ atoms can be seen in the Hirshfeld surfaces as red spots on the $d_{\text {norm }}$ surface in Fig. 6. Other visible spots in the Hirshfeld surfaces correspond to mainly $\mathrm{C} \cdots \mathrm{H} / \mathrm{H} \cdots \mathrm{C}$ and $\mathrm{H} \cdots \mathrm{H}$ contacts. Additionally, the 2D fingerprint plots (Fig. 7) illustrate the difference between the intermolecular interaction patterns and the relative contributions (in percentage) for the major intermolecular interactions associated with the complex. In the 2D fingerprint plot (Fig. 7) intermolecular interactions appear as distinct spikes. The fingerprint plots can also be decomposed to emphasize selected atoms pair close contacts. This decomposition enables separation of contributions from different interaction types, which overlap in the full fingerprint. Relative contributions to the Hirshfeld surface area for the various intermolecular contacts of both complexes are shown in Fig. S1 (ESI $\dagger$ ).

\section{X-ray diffraction of powdered sample}

The X-ray diffraction patterns of the powdered samples are in excellent agreement with those simulated from single crystal $\mathrm{X}$ ray diffraction, confirming the purity of the bulk samples. The simulated patterns of the complexes were calculated from the single crystal structural data using the CCDC Mercury software. Experimental and simulated powder XRD patterns of complexes $\mathbf{1}$ and $\mathbf{2}$ are given in Fig. S2 and S3 respectively (ESI $\dagger$ ).

\section{Spectral and magnetic properties}

The IR spectrum of complex $\mathbf{1}$ exhibits a moderately strong band at $3182 \mathrm{~cm}^{-1}$, which may be ascribed to the $\mathrm{N}-\mathrm{H}$ stretching vibration. No such band is observed in case of complex 2 , because of the absence of $\mathrm{N}-\mathrm{H}$ bond in it. The bands in the range of $3000-2900 \mathrm{~cm}^{-1}$ due to alkyl C-H stretching vibrations are routinely noticed in IR spectra of both complexes. ${ }^{38}$ Sharp bands at 2021 and $2015 \mathrm{~cm}^{-1}$ indicate the presence of monodentate azide coligand in the IR spectra of complexes 1 and 2, respectively. ${ }^{39}$ The distinct bands at $\sim 1625 \mathrm{~cm}^{-1}$ due to the azomethine $(\mathrm{C}=\mathrm{N})$ groups are noticed

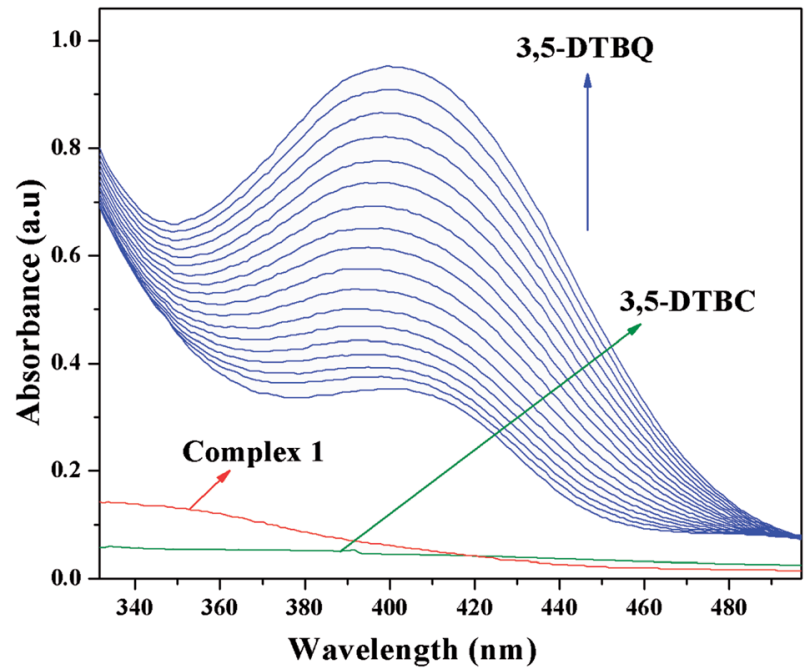

Fig. 9 Time resolved UV-Vis spectral profiles indicating the increment of 3,5-DTBQ peak at $400 \mathrm{~nm}$ upon addition of $10^{-2} \mathrm{M} \mathrm{3,5-DTBC}$ to the $10^{-4} \mathrm{M}$ of complex 1 in acetonitrile-methanol $(2: 1)$ mixture at room temperature.

in the IR spectra of both complexes. ${ }^{40}$ The bands at 1446, $1472 \mathrm{~cm}^{-1}$ (for 1) and 1444, $1469 \mathrm{~cm}^{-1}$ (for 2) are due to the tetrazolate moiety and also observed in other tetrazolate-based metal complexes in previous reports. ${ }^{41}$ IR spectra of complexes 1 and 2 are given in Fig. S4 and S5 respectively (ESI $\dagger$ ).

The electronic spectra $(200-900 \mathrm{~nm})$ of the complexes are similar to each other in acetonitrile-methanol $(2: 1)$ mixture at room temperature. Usually low-spin octahedral cobalt(III) complexes show two broad absorption bands at low energy region due to spin allowed ${ }^{1} \mathrm{~A}_{1 \mathrm{~g}} \rightarrow{ }^{1} \mathrm{~T}_{1 \mathrm{~g}}$ and ${ }^{1} \mathrm{~A}_{1 \mathrm{~g}} \rightarrow{ }^{1} \mathrm{~T}_{2 \mathrm{~g}}$ transitions. ${ }^{42}$ In the present case, complexes 1 and 2 show broad

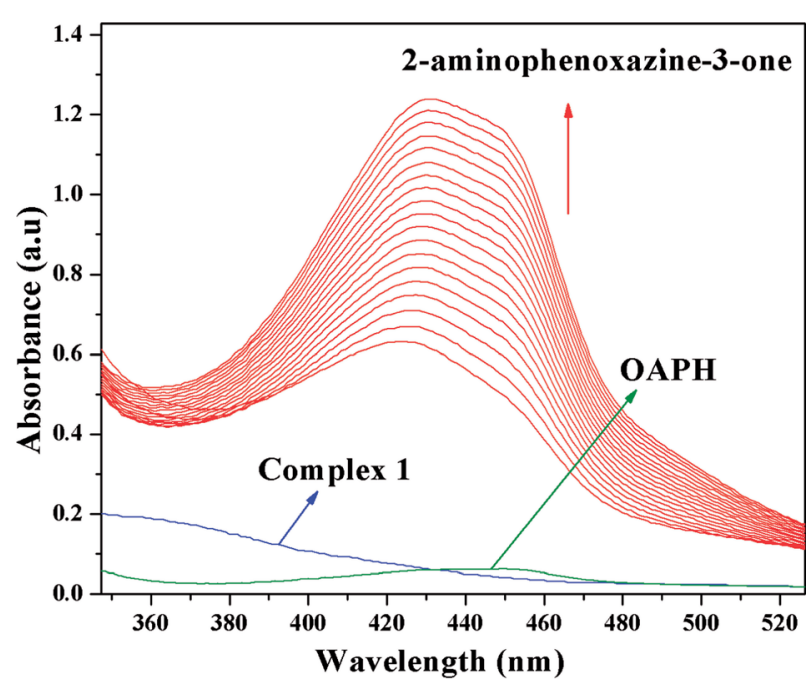

Fig. 10 Time resolved UV-Vis spectral profiles indicating the increment of 0 -aminophenoxazine-3-one peak at $\sim 433 \mathrm{~nm}$ upon addition of $10^{-2} \mathrm{Mo-aminophenol} \mathrm{to} \mathrm{the} 10^{-4} \mathrm{M}$ of complex 1 in acetonitrilemethanol $(2: 1)$ mixture at room temperature. 


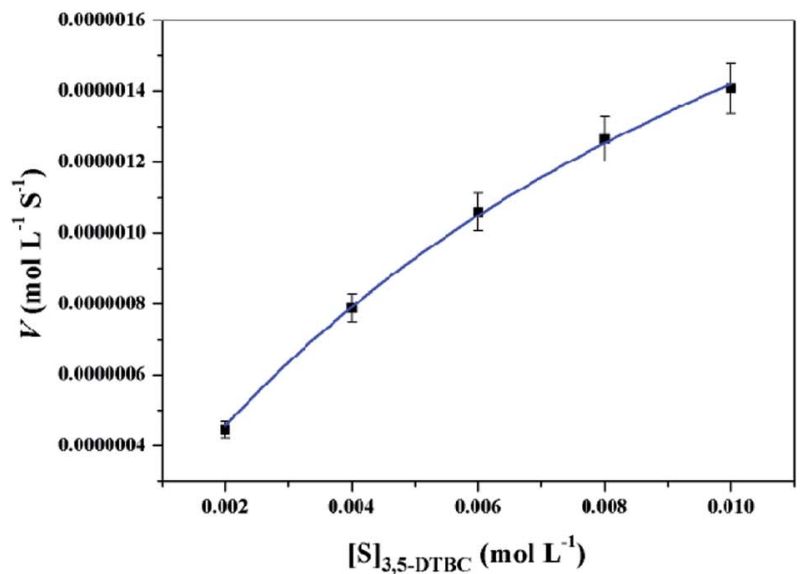

(a)

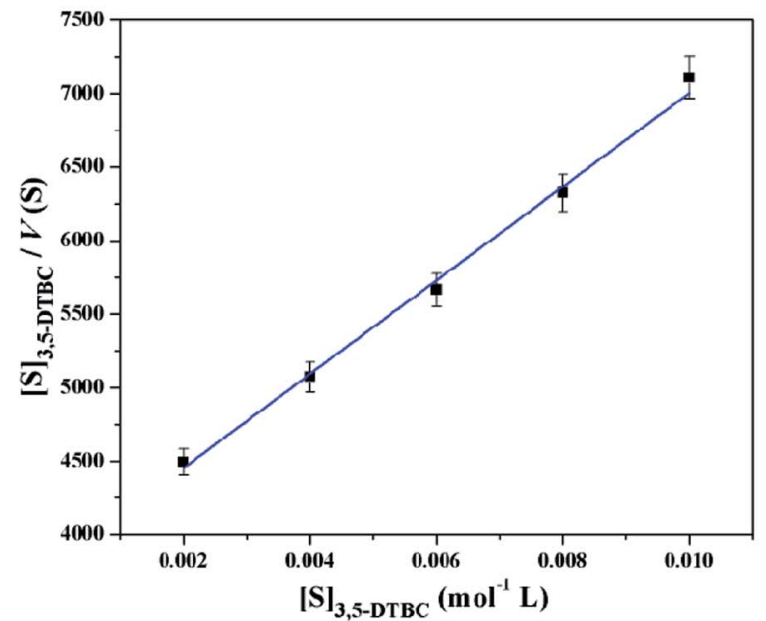

(c)

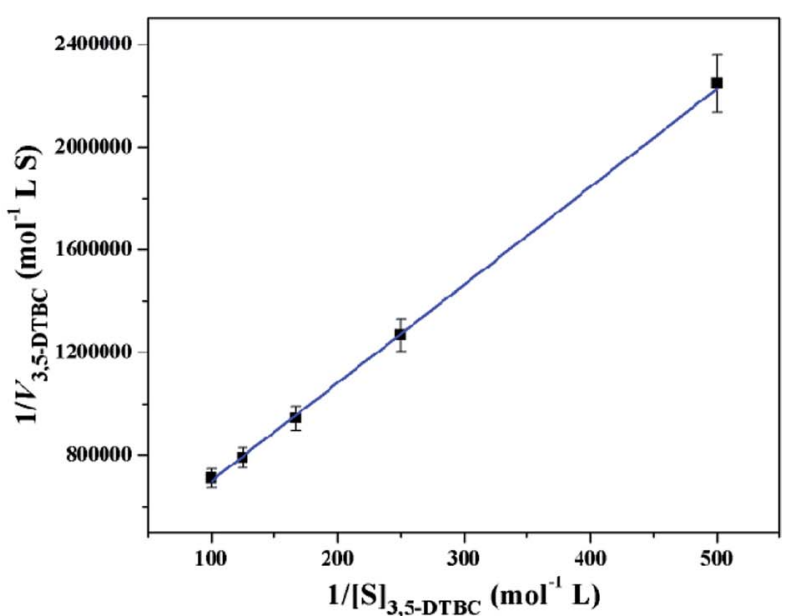

(b)

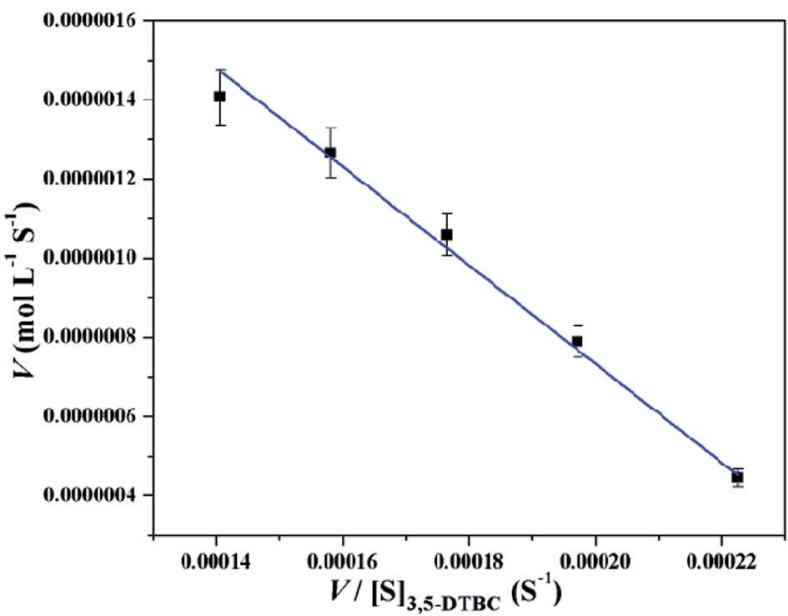

(d)

Fig. 11 Michaelis-Menten plot (a), Lineweaver-Burk plot (b), Hanes plot (c) and Eadie-Hofstee plot (d) of complex 1 for catalytic oxidation of 3,5 -DTBC in acetonitrile-methanol $(2: 1)$ mixture at room temperature.

absorption bands at $670 \mathrm{~nm}$ and $710 \mathrm{~nm}$, respectively, attributable to one of the two expected transitions for any low-spin cobalt(III) in octahedral geometry, as mentioned above. ${ }^{43}$ The intense absorption bands of the complexes, at around $350 \mathrm{~nm}$ may be assigned as charge transfer transitions from the coordinated ligands to the cobalt(III) centers (LMCT) ${ }^{44 a}$ High energy absorption bands around $240 \mathrm{~nm}$ in both complexes may be assigned to intra ligand $\pi-\pi^{*}$ transition. ${ }^{44 b}$ Electronic spectra of $\mathbf{1}$ and $\mathbf{2}$ are given in Fig. S6 and S7 respectively (ESI†).

Both complexes show strong photoluminescence upon the irradiation of ultraviolet light. Upon excitation at around $240 \mathrm{~nm}$, complex 1 emits at $350 \mathrm{~nm}$ whereas complex 2 emits at $380 \mathrm{~nm}$. The excited state mean lifetimes of complexes 1 and 2 are $7.24 \mathrm{~ns}$ and $7.91 \mathrm{~ns}$, respectively (Table 4) Photoluminescence spectra and time dependent photoluminescence decay profile of both complexes is shown in Fig. S8-S10 (ESI†).

Room temperature magnetic susceptibility measurements show that both complexes are diamagnetic as expected for lowspin cobalt(III) complexes. ${ }^{45 a}$

\section{Electrochemical studies}

By scanning in the negative direction initiated at $0.00 \mathrm{~V}$, two reduction peaks are observed. The starting reduction peaks corresponding to $\mathrm{Co}(\mathrm{III}) \rightarrow \mathrm{Co}(\mathrm{II})$ reduction processes are observed at about potential -0.70 and $-0.62 \mathrm{~V}$ for complexes 1 and 2 respectively. Similarly the subsequent reduction peaks of complexes 1 and 2 are observed at -1.80 and $-1.81 \mathrm{~V}$ respectively, which indicate $\mathrm{Co}(\mathrm{II}) \rightarrow \mathrm{Co}(\mathrm{I})$ transformation. The corresponding oxidation peaks are observed during the reverse scan process. The oxidation of $\mathrm{Co}(\mathrm{I}) \rightarrow \mathrm{Co}(\mathrm{II})$ is suggested by the presence of the peaks at -1.84 and $-1.44 \mathrm{~V}$ for complexes 1 and 2 respectively. $\mathrm{Co}(\mathrm{II}) \rightarrow \mathrm{Co}(\mathrm{III})$ oxidation processes are observed at -0.38 and $-0.30 \mathrm{~V}$ for complexes 1 and 2 respectively. The cyclic voltammogram of complex $\mathbf{1}$ is shown in Fig. 8. The quasi-reversible redox reaction may be rationalized by the expected structural changes by elongation of axial bond lengths or losing of axial ligands because of the addition of one electron to $\mathrm{d}_{z^{2}}$ orbital and vice versa. ${ }^{45 b}$ Repeated scans lead to nearly superposable cyclic voltammograms, which suggest all three oxidation states of cobalt are 


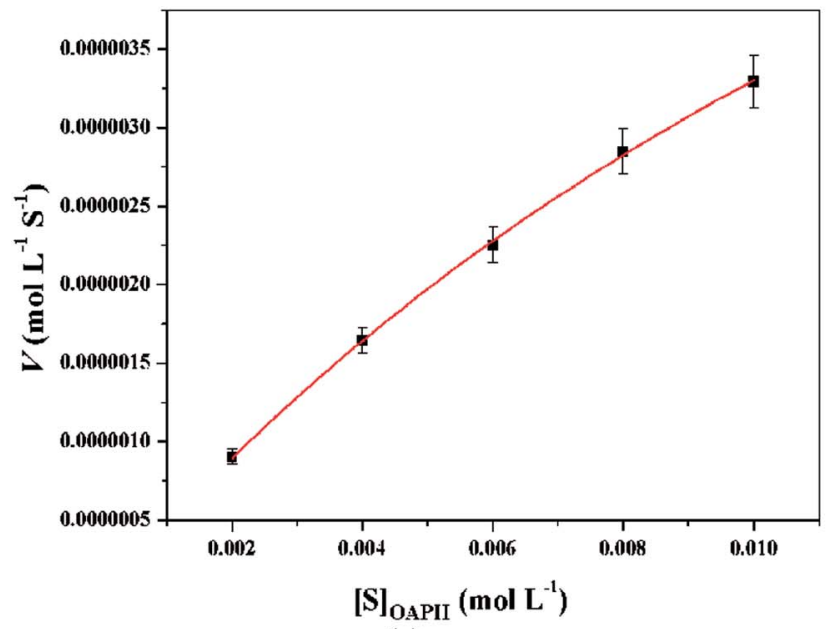

(a)



(c)

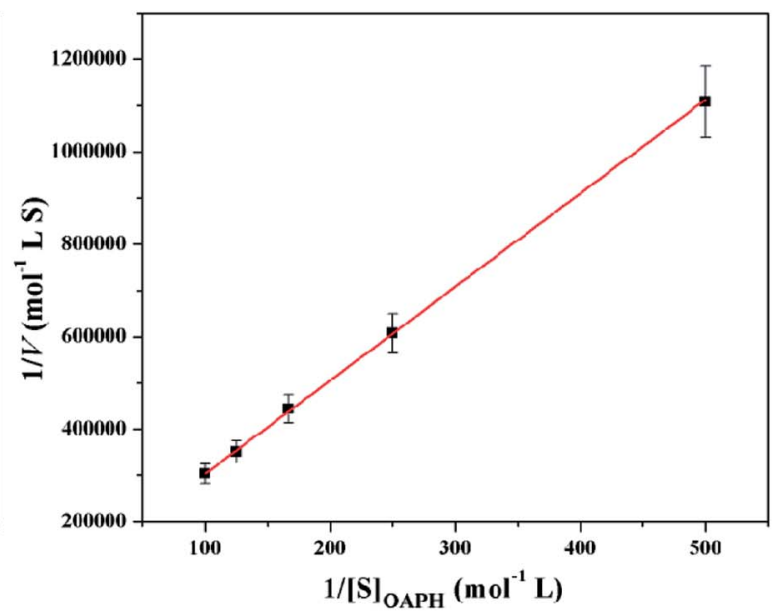

(b)

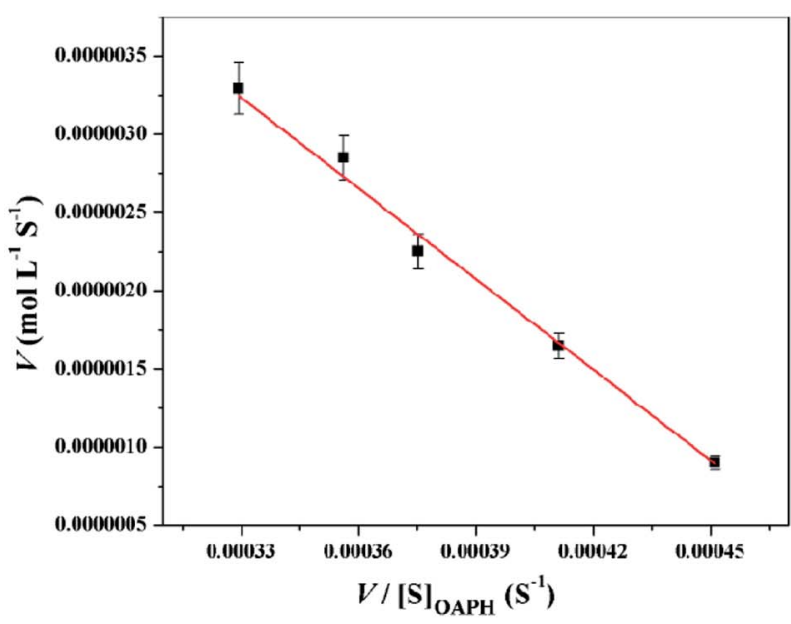

(d)

Fig. 12 Michaelis-Menten plot (a), Lineweaver-Burk plot (b), Hanes plot (c) and Eadie-Hofstee plot (d) of complex 1 for catalytic oxidation of $\mathrm{OAPH}$ in acetonitrile-methanol $(2: 1)$ mixture at room temperature.

markedly stable. The reduction peak potentials are strongly depend on donor strength of the coordinate ligands. Presence good electron withdrawing groups such as 5-(2-pyridyl)tetrazole and azide causes more electron affinity on cobalt center and so a more negative cathodic peak than cobalt Schiff base complexes. ${ }^{45 c}$ The results of cyclic voltammetry also closely resemble that of the similar reported complexes, which serve as further evidences for similar structural and electronic properties. ${ }^{45 b-d}$ The detailed cyclic voltammetry data (V) for both complexes are given in Table 5.

\section{Catalytic activity and kinetic study}

The catalytic experiments were conducted in aerobic condition at room temperature with model substrates 3,5-di-tert-butylcatechol (3,5-DTBC) for catechol oxidase like activity and OAPH ( $o$ aminophenol) for phenoxazinone synthase like activity. Whole catalytic activity was performed in acetonitrile-methanol $(2: 1)$ mixture because of very good solubility of the complexes, substrates and their products. No additional base was added in the reaction medium.

\section{Catechol oxidase mimicking activity}

The catechol oxidase mimicking activity of both complexes was investigated with model substrate 3,5-DTBC. Among the different catechols used in catechol oxidase model studies, 3,5-DTBC is the most widely used substrate because of its low redox potential for the quinone-catechol couple, which makes it easy to be oxidized to the corresponding quinone (3,5-DTBQ), and its bulky substituents help to stop further oxidation reactions, such as ring opening etc. The product (3,5-DTBQ) is significantly stable and it exhibits a strong absorption around $400 \mathrm{~nm}$. So, catechol oxidase mimicking activity and the respective reaction kinetics can be easily followed by UV-visible spectroscopy by following the appearance of the characteristic absorption of the 3,5-DTBQ. The band intensity around $400 \mathrm{~nm}$ is gradually increased as a function of time, suggesting cobalt(III) tetrazolato complexes are capable of exhibiting prominent bio-mimetic catalytic activity related to catechol oxidase. Time resolved UV-Vis spectral profiles indicating the increment of 3,5-DTBQ characteristic peak of complex 1 is shown in Fig. 9. It was found that in the absence of catalyst, no catalytic oxidation of the substrate occurs. 

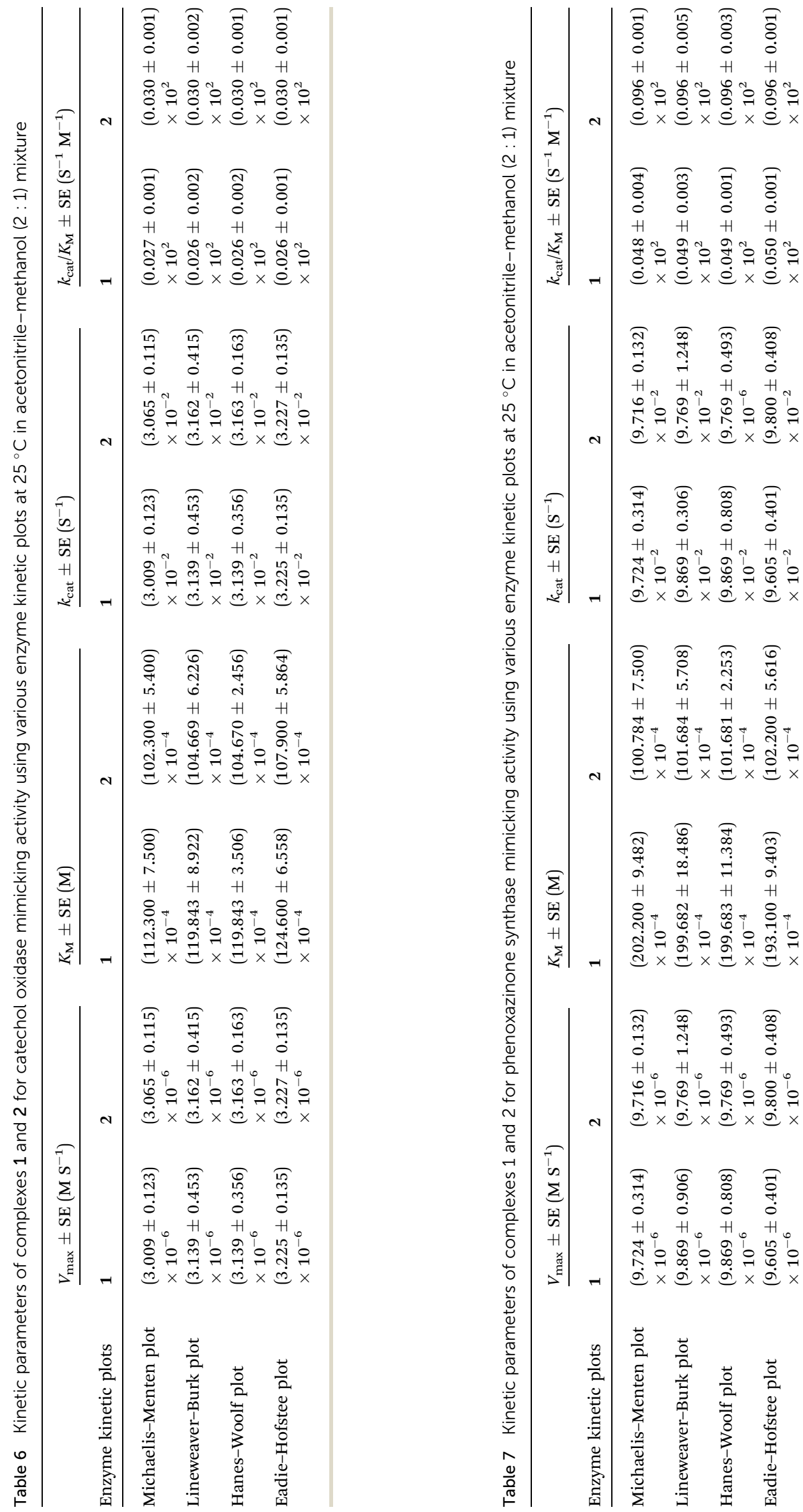


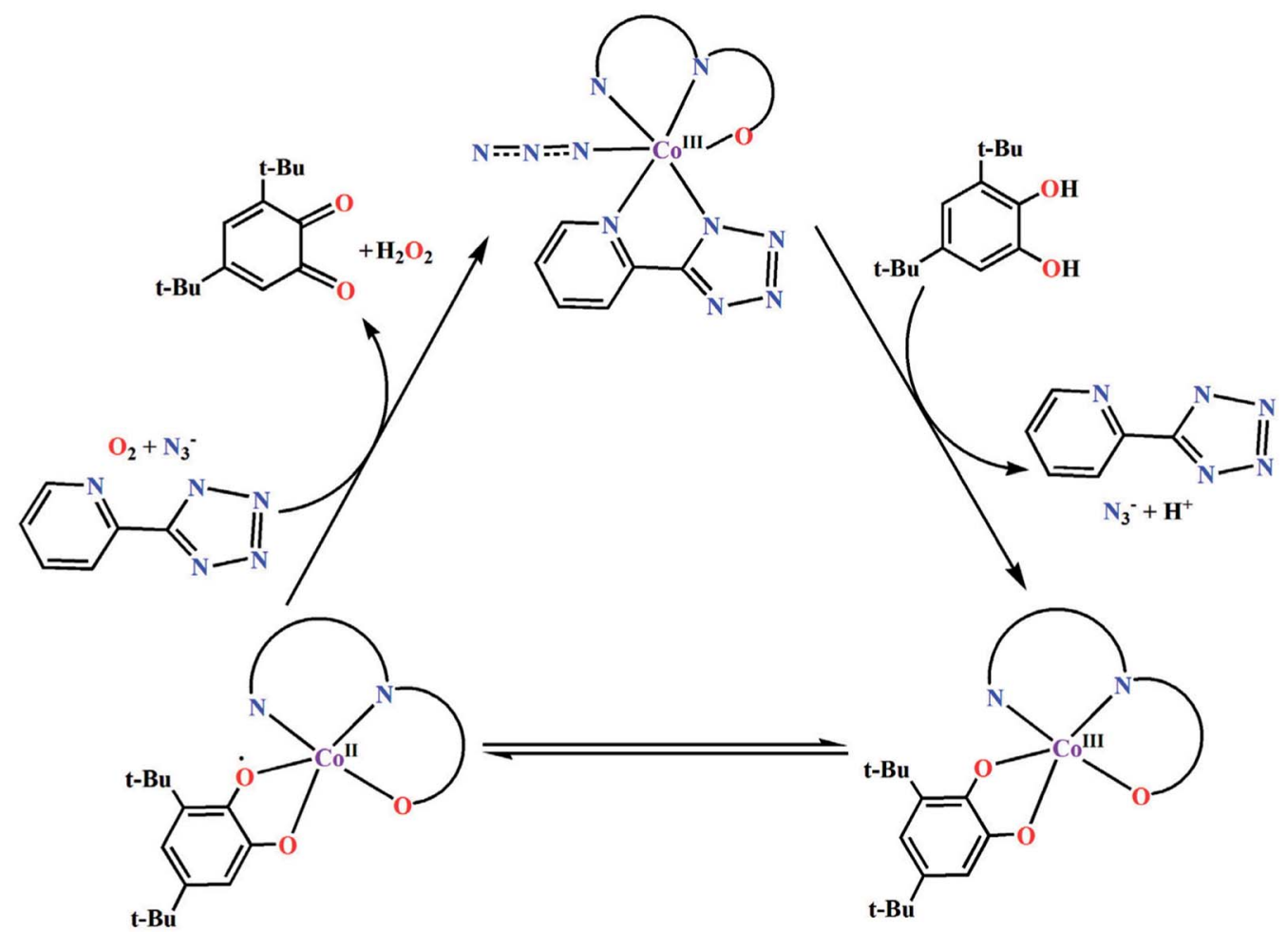

Scheme 3 Proposed mechanistic pathway for the aerial oxidation of 3,5-DTBC catalyzed by complexes 1 and 2.

\section{Phenoxazinone synthase mimicking activity}

It is generally agreed phenoxazinone synthase catalyzes the penultimate step in the biosynthesis of the antibiotic actinomycin D by Streptomyces antibioticus, where oxidative condensation of $o$-aminophenol substituents occurs. Therefore, $o$ aminophenol is used as model substrate for investigating phenoxazinone synthase mimicking activity of both complexes. The oxidative condensation of $o$-aminophenol catalyzed by the complexes was investigated by monitoring the increase of the absorption peak around $433 \mathrm{~nm}$, characteristic of the phenoxazinone chromophore. The spectral scan for both complexes reveal the progressive increase of peak intensity at $c a . \sim 433 \mathrm{~nm}$ suggesting catalytic oxidation of $o$-aminophenol in aerobic condition. The time dependent spectral change for the period of $2 \mathrm{~h}$ after the addition of $o$-aminophenol to the acetonitrile-

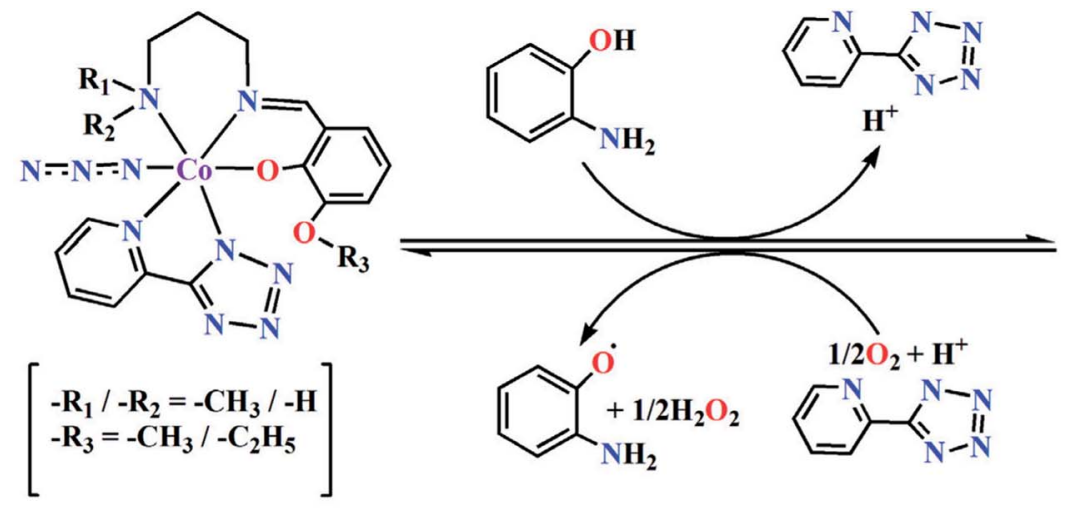

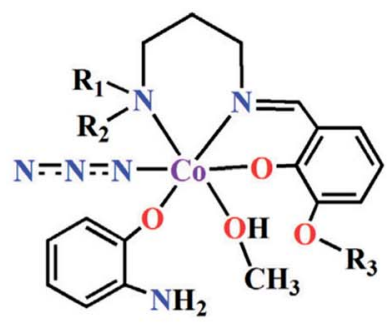

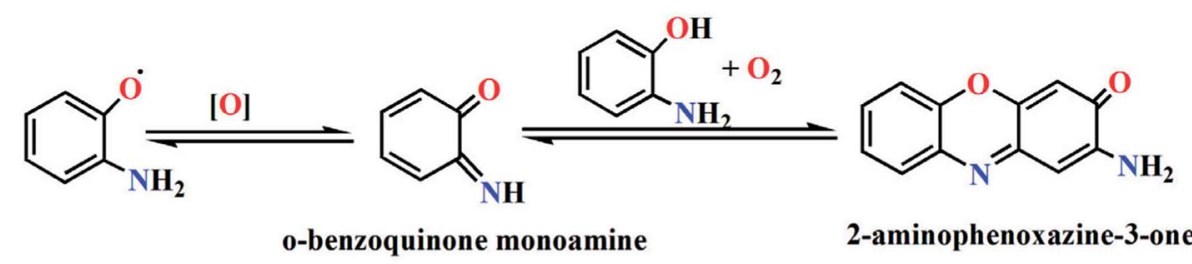

Scheme 4 Proposed mechanistic pathway for the aerial oxidation of 0 -aminophenol catalyzed by complexes 1 or 2 . 
Table 8 A comparison of catechol oxidase mimicking activity of previously reported cobalt based complexes ${ }^{a}$

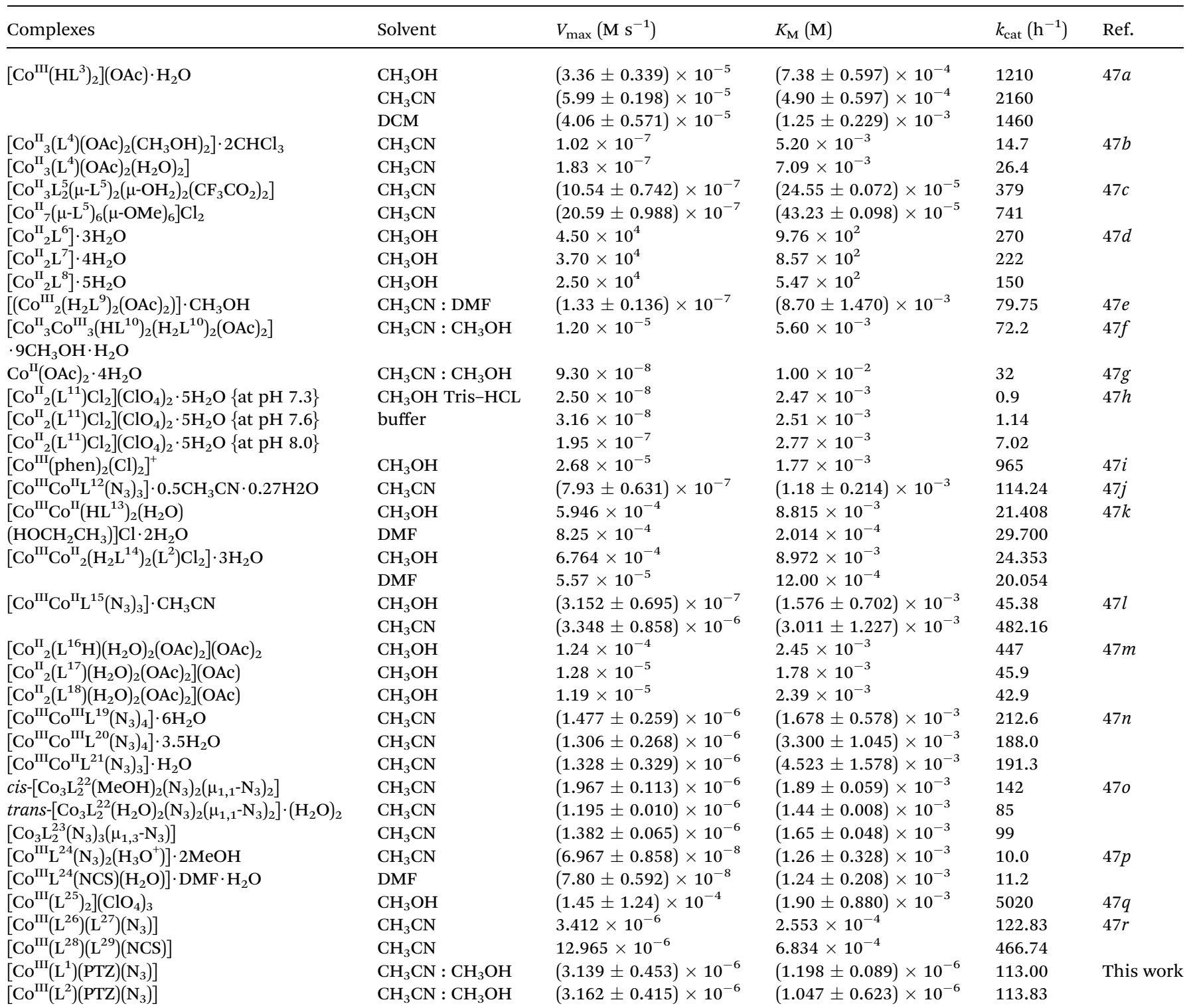

${ }^{a}$ Where, $\mathrm{H}_{2} \mathrm{~L}^{3}=N$-(2-hydroxyethyl)-3-methoxysalicylaldimine; $\mathrm{H}_{4} \mathrm{~L}^{4}=$ condensation product of 2,3-dihydroxynaphthalene-1,4-dicarbaldehyde and 2 -[O-(1-ethyloxyamide)]oxime-4,6-dibromophenol; $\mathrm{HL}^{5}=2-\left\{(3\right.$-ethoxypropylimino)methyl $\}-6$-methoxyphenol; $\mathrm{H}_{2} \mathrm{~L}^{6}=1: 2$ condensation product of 1,2,4,5-tetra-amino benzene and 2-hydroxy benzaldehyde; $\mathrm{H}_{2} \mathrm{~L}^{7}=1: 2$ condensation product of 1,2,4,5-tetra-amino benzene and 2,4-dihydroxy benzaldehyde; $\mathrm{H}_{2} \mathrm{~L}^{8}=1: 2$ condensation product of 1,2,4,5-tetra-amino benzene and 2-hydroxy naphthaldehyde; $\mathrm{H}_{4} \mathrm{~L}^{9}=3,5$-di-tert-butyl-2hydroxybenzylideneamino)-2-(hydroxymethyl)propane-1,3-diol; $\quad \mathrm{H}_{4} \mathrm{~L}^{10}=2$-(3,5-di-tert-butyl-2-hydroxybenzylideneamino)-2-(hydroxymethyl) propane-1,3-diol; $\mathrm{L}^{11}=N, N, N^{\prime}, N^{\prime}$-tetrakis $\left(2^{\prime}\right.$-benzimidazolylmethyl)-1,4-diethylene amino glycol ether; phen $=1,10$-phenanthroline; $\mathrm{H}_{2} \mathrm{~L}^{12}=[2+$ 2] condensation product of 2,6-diformyl-4-methylphenol and 2,2-dimethyl-1,3-diaminopropane; $\mathrm{H}_{3} \mathrm{~L}^{13}=3$-[(2-hydroxy-benzylidene)-amino]propane-1,2-diol; $\mathrm{H}_{3} \mathrm{~L}^{14}=3$-[(2-hydroxy-3-methoxy-benzylidene)-amino]-propane-1,2-diol; $\mathrm{H}_{2} \mathrm{~L}^{15}=[2+2]$ condensation of 4-ethyl-2,6diformylphenol and 2,2'-dimethyl-1,3-diaminopropane; $\mathrm{HL}^{16}=2,6$-bis( $N$-ethylpiperazine-iminomethyl)-4-methyl-phenolato; $\mathrm{HL}^{17}=2,6$-bis(2ethylpyridine-iminomethyl)-4-methyl-phenolato; $\mathrm{HL}^{18}=2,6$-bis( $\left(N\right.$-ethylpiperidine-iminomethyl)-4-methyl-phenolato; $\mathrm{H}_{2} \mathrm{~L}^{22}=\quad N, N^{\prime}$ bis(salicylidene)-1,3-propanediamine; $\quad \mathrm{H}_{2} \mathrm{~L}^{23}=N, N^{\prime}$-bis(2-hydroxybenzyl)-1,3-propanediamine; $\mathrm{H}_{2} \mathrm{~L}^{24}=\quad N^{24}, N^{\prime}$-ethylenebis(3ethoxysalicylaldiimine); $\mathrm{L}^{25}=$ condensation product of 1,3 -propanediamine and 2-benzoylpyridine; $\mathrm{HL}^{26}=2((2$ (piperidin-1-yl)ethylimino) methyl)-6-ethoxyphenol; $\mathrm{HL}^{27}=1$-acetyl-2-naphthol; $\mathrm{HL}^{28}=2$-((3(dimethylamino)propylimino)methyl)-6-methoxyphenol; $\mathrm{HL}^{29}=2,4-$ pentanedione.

methanol $(2: 1)$ mixture of complex 1 is depicted in Fig. 10. It should be noted at this point that a blank experiment without catalyst (complex) does not show significant growth of the band at $\sim 433 \mathrm{~nm}$, characteristic of phenoxazinone chromophore, in an identical reaction condition.

\section{Kinetic parameters and explanation of the turnover numbers}

Michaelis-Menten model is an important tool to treat this type of saturation rate dependency on the concentration of the substrate. The Michaelis-Menten equation: 
Table 9 A comparison of phenoxazinone synthase mimicking activity of previously reported cobalt based complexes ${ }^{a}$

\begin{tabular}{|c|c|c|c|c|c|}
\hline Complexes & Solvent & $V_{\max }\left(\mathrm{M} \mathrm{s}^{-1}\right)$ & $K_{\mathrm{M}}(\mathrm{M})$ & $k_{\text {cat }}\left(\mathrm{h}^{-1}\right)$ & Ref. \\
\hline \multirow[t]{2}{*}[\mathrm{Co}^{\mathrm{III}}(\mathrm{L}^{25})_{2}]{$\left(\mathrm{ClO}_{4}\right)_{3}$} & $\mathrm{CH}_{3} \mathrm{OH}$ & $(1.27 \pm 0.915) \times 10^{-4}$ & $(3.84 \pm 0.847) \times 10^{-3}$ & 4590 & \multirow[t]{2}{*}{$47 q$} \\
\hline & $\mathrm{CH}_{3} \mathrm{CN}$ & $(1.42 \pm 0.985) \times 10^{-4}$ & $(6.04 \pm 1.04) \times 10^{-4}$ & 5120 & \\
\hline \multicolumn{6}{|l|}{$\left.\left(\mathrm{C}_{6} \mathrm{H}_{5} \mathrm{CO}_{2}^{-}\right)_{2}\right] \cdot\left(\mathrm{CH}_{3} \mathrm{CN}\right)_{2}$} \\
\hline$\left[\mathrm{Co}^{\mathrm{III}}\left(\mathrm{L}^{30}\right)\left(\mathrm{N}_{3}\right)_{2}\right] \cdot 0.5 \mathrm{CH}_{3} \mathrm{CN}$ & $\mathrm{CH}_{3} \mathrm{OH}$ & $3.00 \times 10^{-7}$ & $1.35 \times 10^{-2}$ & 54.0 & \multirow[t]{2}{*}{$48 b$} \\
\hline$\left[\mathrm{Co}^{\mathrm{III}}\left(\mathrm{L}^{30}\right)(\mathrm{NCS})_{2}\right] \cdot 0.5 \mathrm{H}_{2} \mathrm{O}$ & $\mathrm{CH}_{3} \mathrm{OH}$ & $2.70 \times 10^{-7}$ & $1.24 \times 10^{-2}$ & 48.6 & \\
\hline$\left[\mathrm{Co}^{\mathrm{III}}\left(\mathrm{L}^{31}\right)_{2}\left(\mathrm{~L}^{32}\right)_{2}\right]-\mathrm{Cl} \cdot 8 \mathrm{H}_{2} \mathrm{O}$ & $\mathrm{CH}_{3} \mathrm{OH}$ & $1.70 \times 10^{-7}$ & $6.08 \times 10^{-3}$ & 30.6 & $48 c$ \\
\hline$\left[\mathrm{Co}^{\mathrm{III}}\left(\mathrm{HL}^{33}\right)_{2}\right](\mathrm{OAc}) \cdot \mathrm{H}_{2} \mathrm{O}$ & $\mathrm{CH}_{3} \mathrm{OH}$ & $(7.87 \pm 0.541) \times 10^{-4}$ & $(4.31 \pm 0.775) \times 10^{-4}$ & 28300 & $48 d$ \\
\hline$\left[\mathrm{Co}^{\mathrm{III}} \mathrm{L}^{34}\left(\mathrm{~L}^{35}\right) 2\right] \mathrm{ClO}_{4} \cdot \mathrm{MeOH} \cdot \mathrm{H}_{2} \mathrm{O}$ & $\mathrm{CH}_{3} \mathrm{OH}$ & $3.19 \times 10^{-8}$ & $6.785 \times 10^{-4}$ & 11.48 & \multirow[t]{2}{*}{$48 e$} \\
\hline$\left[\mathrm{Co}^{\mathrm{III}} \mathrm{L}^{34}\left(\mathrm{~L}^{36}\right)_{2} \mathrm{Na}\left(\mathrm{ClO}_{4}\right)_{2}\right] \cdot 0.5 \mathrm{H}_{2} \mathrm{O}$ & $\mathrm{CH}_{3} \mathrm{OH}$ & $7.75 \times 10^{-8}$ & $2.356 \times 10^{-3}$ & 27.90 & \\
\hline$\left[\mathrm{Co}_{2}{ }^{\mathrm{III}}\left(\mathrm{L}^{37}\right)_{2}\left(\mu-\mathrm{L}^{38}\right)_{2} \mathrm{Cl}_{2}\right] \mathrm{Cl}_{2} \cdot 2 \mathrm{H}_{2} \mathrm{O}$ & $\mathrm{CH}_{3} \mathrm{OH}$ & $1.91 \times 10^{-7}$ & $1.57 \times 10^{-3}$ & 13.752 & $9 f$ \\
\hline$\left[\mathrm{Co}^{\mathrm{III}}\left(\mathrm{L}^{39}\right)\left(\mathrm{N}_{3}\right)_{3}\right]$ & $\mathrm{CH}_{3} \mathrm{OH}$ & $(5.66 \pm 0.32) \times 10^{-8}$ & $(7.12 \pm 0.72) \times 10^{-3}$ & 20.37 & $46 b$ \\
\hline$\left[\mathrm{Co}^{\mathrm{II}}\left(\mathrm{L}^{44}\right)\left(\mathrm{H}_{2} \mathrm{O}\right)\right]\left(\mathrm{ClO}_{4}\right)_{2}$ & $\mathrm{CH}_{3} \mathrm{OH}$ & $(3.54 \pm 0.06) \times 10^{-8}$ & $(1.28 \pm 0.15) \times 10^{-2}$ & 6.37 & $48 f$ \\
\hline$\left[\mathrm{Co}^{\mathrm{II}}\left(\mathrm{L}^{45}\right)\left(\mathrm{H}_{2} \mathrm{O}\right)\right]\left(\mathrm{ClO}_{4}\right)_{2}$ & $\mathrm{CH}_{3} \mathrm{OH}$ & $(4.60 \pm 0.08) \times 10^{-8}$ & $(1.32 \pm 0.17) \times 10^{-2}$ & 8.28 & $48 f$ \\
\hline$\left[\mathrm{CO}^{\mathrm{II}}\left(\mathrm{L}^{46}\right) \mathrm{Cl}\left(\mathrm{H}_{2} \mathrm{O}\right)\right] \mathrm{Cl} \cdot \mathrm{H}_{2} \mathrm{O}$ & $\mathrm{CH}_{3} \mathrm{OH}$ & $(3.80 \pm 0.31) \times 10^{-7}$ & $(2.0 \pm 0.30) \times 10^{-2}$ & 13.68 & \multirow[t]{3}{*}{$48 g$} \\
\hline$\left[\mathrm{Co}^{\mathrm{II}}\left(\mathrm{L}^{46}\right)(\mathrm{NCS})_{2}\right]$ & $\mathrm{CH}_{3} \mathrm{OH}$ & $(2.05 \pm 0.22) \times 10^{-7}$ & $(1.9 \pm 0.30) \times 10^{-2}$ & 7.38 & \\
\hline$\left[\mathrm{Co}^{\mathrm{II}}\left(\mathrm{L}^{47}\right) \mathrm{Cl}_{2}\right]$ & $\mathrm{CH}_{3} \mathrm{OH}$ & $(1.14 \pm 0.05) \times 10^{-7}$ & $(1.6 \pm 0.90) \times 10^{-2}$ & 4.10 & \\
\hline$\left[\mathrm{Co}^{\mathrm{III}}\left(\mathrm{L}^{48}\right)\left(\mathrm{L}^{49}\right)\left(\mathrm{N}_{3}\right)\right]$ & $\mathrm{CH}_{3} \mathrm{CN}$ & $6.73 \times 10^{-6}$ & $5.08 \times 10^{-4}$ & 247.2 & \multirow[t]{2}{*}{$48 h$} \\
\hline$\left[\mathrm{Co}^{\mathrm{III}}\left(\mathrm{L}^{48}\right)\left(\mathrm{L}^{49}\right)(\mathrm{NCS})\right]$ & $\mathrm{CH}_{3} \mathrm{CN}$ & $7.15 \times 10^{-6}$ & $5.75 \times 10^{-4}$ & 257.4 & \\
\hline$\left[\mathrm{Co}^{\mathrm{III}}\left(\mathrm{L}^{50}\right)\left(\mathrm{L}^{51}\right)\left(\mathrm{N}_{3}\right)\right]$ & $\mathrm{CH}_{3} \mathrm{CN}$ & $2.153 \times 10^{-6}$ & $1.613 \times 10^{-5}$ & 77.52 & \multirow[t]{2}{*}{45} \\
\hline$\left[\mathrm{Co}\left(\mathrm{L}^{52}\right)\left(\mathrm{L}^{49}\right)\left(\mathrm{N}_{3}\right)\right]$ & $\mathrm{CH}_{3} \mathrm{CN}$ & $2.003 \times 10^{-6}$ & $1.565 \times 10^{-5}$ & 72.12 & \\
\hline$\left[\mathrm{Co}^{\mathrm{III}}\left(\mathrm{L}^{26}\right)\left(\mathrm{L}^{27}\right)\left(\mathrm{N}_{3}\right)\right]$ & $\mathrm{CH}_{3} \mathrm{CN}$ & $4.629 \times 10^{-6}$ & $0.676 \times 10^{-4}$ & 166.64 & \multirow[t]{2}{*}{$47 r$} \\
\hline$\left[\mathrm{Co}^{\mathrm{III}}\left(\mathrm{L}^{28}\right)\left(\mathrm{L}^{29}\right)(\mathrm{NCS})\right]$ & $\mathrm{CH}_{3} \mathrm{CN}$ & $17.400 \times 10^{-6}$ & $3.238 \times 10^{-4}$ & 626.40 & \\
\hline$\left[\mathrm{Co}^{\mathrm{III}}\left(\mathrm{L}^{1}\right)(\mathrm{PTZ})\left(\mathrm{N}_{3}\right)\right]$ & $\mathrm{CH}_{3} \mathrm{CN}: \mathrm{CH}_{3} \mathrm{OH}$ & $(9.869 \pm 0.906) \times 10^{-6}$ & $(199.682 \pm 18.486) \times 10^{-4}$ & 355.28 & This work \\
\hline
\end{tabular}

${ }^{a}$ Where, $\mathrm{HL}^{30}=$ condensation product of $N, N$-dimethyldipropylenetriamine and $o$-vanillin; $\mathrm{H}_{2} \mathrm{~L}^{31}=3,5,6$-tribromo-4-pyridiniumcatechol; $\mathrm{L}^{32}=$ pyridine; $\mathrm{H}_{2} \mathrm{~L}^{33}=N$-(2-hydroxyethyl)-3-methoxysalicylaldimine; $\mathrm{H}_{2} \mathrm{~L}^{34}=N, N^{\prime}$-bis(3-methoxysalicylidehydene)cyclohexane-1,2-diamine); $\mathrm{L}^{35}=4$ aminopyridine; $\mathrm{L}^{36}=1$-methylimidazole; $\mathrm{L}^{37}=2$-aminomethylpyridine; $\mathrm{L}^{38}=2$-iminomethylpyridine anion; $\mathrm{L}^{39}=$ bis $(2$-pyridylmethyl)amine; $\mathrm{L}^{40}=$ (2-pyridylmethyl)(2-pyridylethyl)amine; $\mathrm{L}^{41}=1: 2$ condensation product of $3,3^{\prime}$-bisaminopropylamine and 2 -pyridinecarboxaldehyde; $\mathrm{L}^{42}$ $=1: 2$ condensation product of $3,3^{\prime}$-bisaminopropylamine and 2 -acetylpyridine; $\mathrm{L}^{43}=1: 2$ condensation product of diethylenetriamine and 2 pyridinecarboxaldehyde; $\mathrm{L}^{44}=1: 2$ condensation product of $3,3^{\prime}$-bisaminopropylamine and 6 -methyl-2-pyridinecarboxaldehyde; $\mathrm{L}^{45}=1: 2$ condensation product of 3,3'-diamino- $N$-methyldipropylamine and 6-methyl-2-pyridinecarboxaldehyde; $\mathrm{L}^{46}=N, N^{\prime}$-bis(pyridin-2-ylmethylene)-2,2dimethylpropane-1,3-diamine; $\mathrm{L}^{47}=N, N^{\prime}$-bis(6-methylpyridin-2-ylmethylene)-2,2-dimethylpropane-1,3-diamine; $\mathrm{HL}^{48}=2$-(3-(dimethylamino) propyliminomethyl)-6-ethoxyphenol; $\mathrm{HL}^{49}=1$-benzoylacetone; $\mathrm{HL}^{50}=2\left((2\right.$ (2-hydroxyethylamino)ethylimino $)$ methyl)-6-ethoxyphenol, $\mathrm{HL}^{51}=2$ acetyl-1-naphthol; $\mathrm{HL}^{52}=1((2$ (diethylamino)ethylimino)methyl)naphthalen-2-ol.

$$
V=\frac{V_{\max }[\mathrm{S}]}{K_{\mathrm{M}}+[\mathrm{S}]}
$$

where, $V=$ initial rate; $[\mathrm{S}]=$ concentration of the substrates; $K_{\mathrm{M}}$ $=$ Michaelis-Menten constant for the metal complex and $V_{\max }=$ maximum initial rate attained for a particular concentration of the metal complex in the presence of a large excess of the substrate.

On the other hand, rearrangement of Michaelis-Menten equation produces Lineweaver-Burk equation (eqn (2)), Hanes equation (eqn (3)) and Eadie-Hofstee equation (eqn (4)).

$$
\begin{gathered}
\frac{1}{V}=\frac{K_{\mathrm{M}}}{V_{\max }} \frac{1}{[\mathrm{~S}]}+\frac{1}{V_{\max }} \\
\frac{[\mathrm{S}]}{V}=\frac{[\mathrm{S}]}{V_{\max }}+\frac{K_{\mathrm{M}}}{V_{\max }}
\end{gathered}
$$

$$
V=V_{\max }-K_{\mathrm{M}} \frac{V}{[\mathrm{~S}]}
$$

All these equations are used to analyze a variety of kinetic parameters, including turnover number $\left(k_{\text {cat }}\right)$ and specificity constant $\left(k_{\mathrm{cat}} / K_{\mathrm{M}}\right)$ for catechol oxidase and phenoxazinone synthase mimicking activity of synthesized complexes. Kinetic parameters like $V_{\max }$ and $K_{\mathrm{M}}$ were calculated by the analysis of entire experimental data. The turnover number value $\left(k_{\text {cat }}\right)$ is obtained by dividing the $V_{\max }$ by the concentration of the catalyst (complex) used. Fig. 11 and 12 represent the MichaelisMenten plot, Lineweaver-Burk plot, Hanes plot and EadieHofstee plot of complex 1 for catalytic oxidation of 3,5-DTBC and OAPH, respectively. Similarly, the Michaelis-Menten plot, Lineweaver-Burk plot, Hanes plot and Eadie-Hofstee plot of complex 2 for catalytic oxidation of 3,5-DTBC and OAPH are 


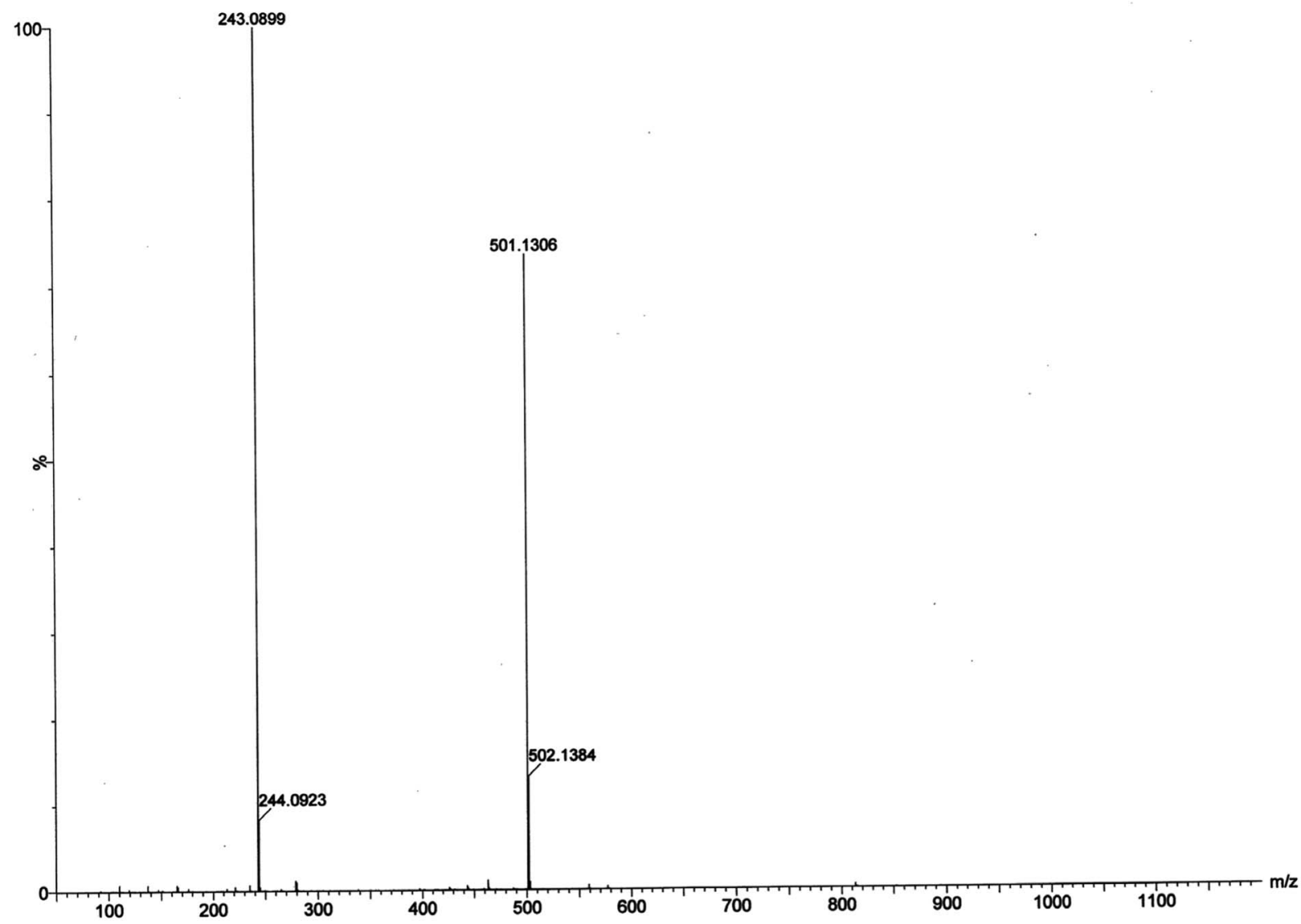

Fig. 13 ESI-MS positive spectrum of $1: 50$ mixture of complex 1 and 3,5-DTBC in acetonitrile-methanol (2:1) mixture at room temperature.

given in Fig. S11 and S12 (ESI†), respectively. Tables 6 and 7 contain all kinetic parameters of the complexes for catechol oxidase and phenoxazinone synthase like activity, respectively. In order to calculate kinetic parameters more accurately, several enzyme kinetic plots have been used. More or less similar kinetic parameters have been obtained in all cases and this indicates the accuracy of the experimental results. The $k_{\text {cat }}$ value suggest that both complexes are very effective catalyst for the conversation of 3,5-DTBC to 3,5-DTBQ and $o$-aminophenol to 2aminophenoxazine-3-one.

\section{Origin and mechanistic pathway of catalytic activity}

Based on the above experimental results, it is clear that both complexes are very reactive towards the catechol oxidase and phenoxazinone synthase mimicking activity. Schemes 3 and 4 represent possible mechanism for catalytic conversation of 3,5DTBC to 3,5-DTBQ and $o$-aminophenol to 2 -aminophenoxazine3-one, respectively. It is easily understandable that at initial step of the catalytic cycles, the tetrazole moiety and/or monodentate azide co-ligand were replaced by the substrate, thereby forming a substrate-catalyst adduct. Hence it may be stated that the replacement of tetrazole moiety and/or monodentate azide coligand initiated the catalytic cycles. This substrate-catalyst adduct yields a substrate radical in the rate determining step. Finally, quinone chromophore was formed from this substrate radical via a number of oxidative dehydrogenation processes.
The catalytic activity depends on the interaction between substrate and catalyst. Higher the interaction between substrate and catalyst higher the $k_{\text {cat }}$ values (Tables 6 and 7). Both complexes have comparable turnover numbers. Similar types of tentative catalytic cycles have also been proposed by several other groups. ${ }^{46}$

A detailed literature survey with cobalt based model complexes for catechol oxidase and phenoxazinone synthase mimicking activities has shown that several factors may affect their catalytic activity, such as the oxidation state of the metal, coordination geometry around the metal center, metal-metal distance, ligand flexibility, exogenous bridging ligand etc. ${ }^{47,48}$ All these cobalt based model complexes showing catechol oxidase and phenoxazinone synthase mimicking activity are gathered in Tables 8 and 9 respectively along with several kinetic parameters such as $K_{\mathrm{M}}, V_{\max }$ and $k_{\text {cat }}$. As the turnover numbers $\left(k_{\text {cat }}\right.$ values) of both complexes fall in between the range, they may be considered as moderate catalysts.

\section{Experimental and theoretical proof behind proposed mechanistic pathways}

\section{Experimental proof}

Electrospray ionization mass spectral analysis. The electrospray ionization mass spectral analysis (ESI-MS positive) of 


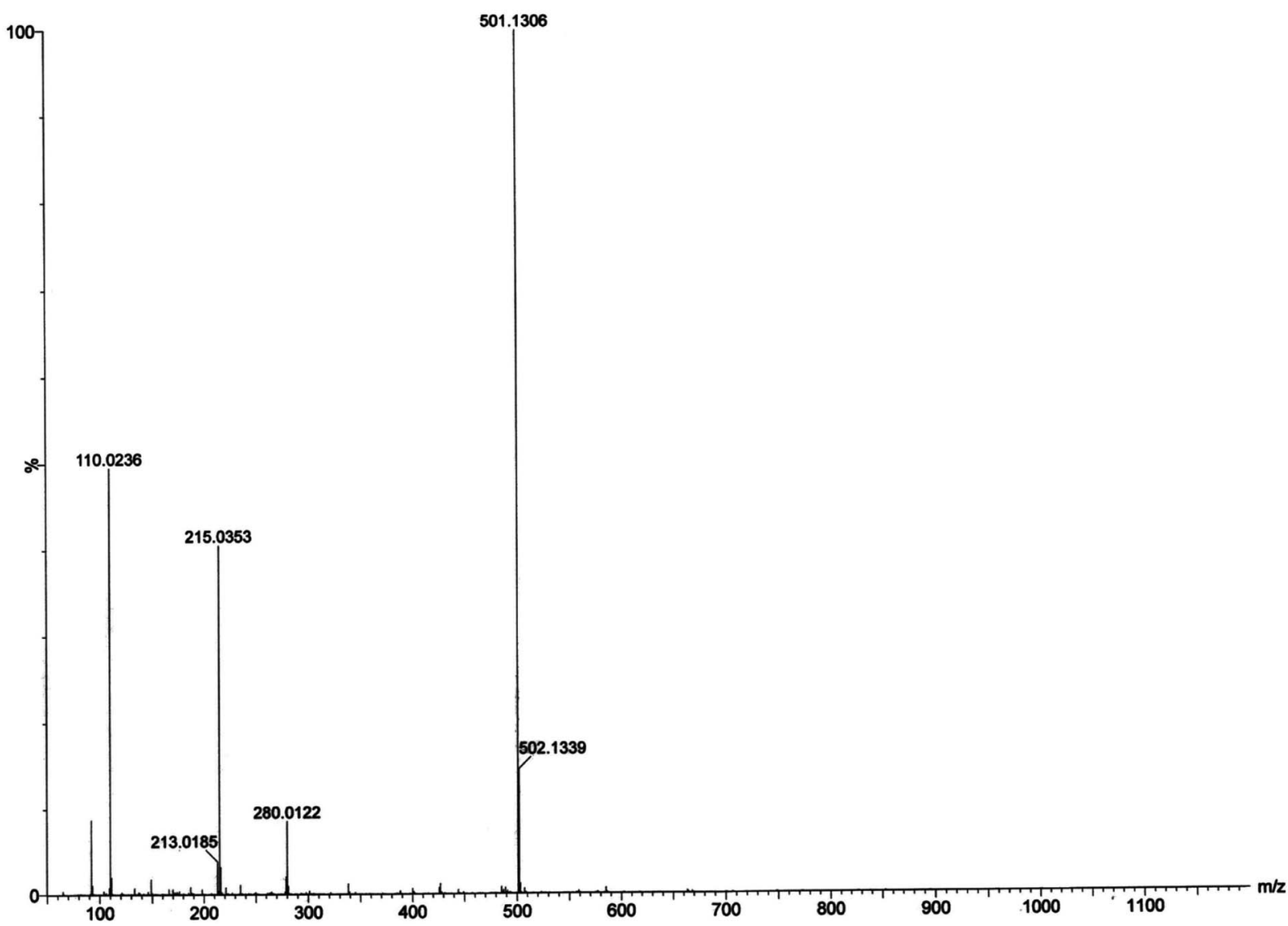

Fig. 14 ESI-MS positive spectrum of $1: 50$ mixture of complex 1 and 0 -aminophenol in acetonitrile-methanol (2:1) mixture at room temperature.

complex 1 in presence of substrate (3,5-DTBC for catechol oxidase mimicking activity and $o$-aminophenol for phenoxazinone synthase mimicking activity) in acetonitrile-methanol $(2: 1)$ mixture were recorded to get inside the catalytic cycles. Complex 1 was taken as a model complex. ESI-MS positive spectra of a $1: 50$ mixture of the complex 1 with 3,5-DTBC and $o$-aminophenol were recorded separately after $5 \mathrm{~min}$ of mixing in acetonitrile-methanol $(2: 1)$ mixture and the results are depicted in Fig. 13 and 14, respectively. The most attentiongrabbing observation from the mass spectral study is the appearance of peaks related to substrate-catalyst intermediate species. For catechol oxidase and phenoxazinone synthase mimicking activity of the complex $\mathbf{1}$, mass peaks around $\mathrm{m} / \mathrm{z} \sim$ 501 indicate the substrate-catalyst intermediate species, [Co- $\mathrm{L}^{1}$ (3,5-DTBC)-H $]^{+}$and $\left[\mathrm{Co}^{-} \mathrm{L}^{1}-\mathrm{N}_{3}-(\mathrm{OAPH})-\mathrm{CH}_{3} \mathrm{OH}-\mathrm{K}\right]^{+}$, respectively. These peaks verify that the catalytic cycles proceed through a stable substrate-catalyst intermediate formation.

In presence of 3,5-DTBC, the mass spectrum exhibits a peak at $m / z=243.0899$ corresponding to quinone sodium aggregate [3,5-DTBQ-Na $]^{+}$, confirming the catechol oxidase mimicking activity of complex 1 . On the other hand, in presence of $o$ aminophenol a peak appears at $\mathrm{m} / z=215.0353$ which corresponds the formation of [phenoxazinone- $\mathrm{H}]^{+}$. This confirms phenoxazinone synthase mimicking activity of the complex. Electrospray ionization mass spectral analysis (ESI-MS positive) of complex 1 in acetonitrile-methanol $(2: 1)$ mixture is given in S13 (ESI $\dagger$ ). Peak around $m / z \sim 477$ indicates the formation of $\left[\mathrm{Co}-\mathrm{L}^{1}-\mathrm{N}_{3}-\mathrm{OCH}_{3}-2\left(\mathrm{CH}_{3} \mathrm{CN}\right)-\mathrm{K}\right]^{+}$(loss of tetrazole moiety) which is the initial step of catalyses. The proposed mechanistic pathways (Schemes 3 and 4) are therefore justified by the mass spectral analysis.

Electron paramagnetic resonance spectral analysis. Electron paramagnetic resonance spectroscopy is a very helpful tool to monitor the generation of radical intermediate during catalytic cycles. As radical is formed as an intermediate species in our proposed mechanistic pathways, EPR measurements at room temperature have been performed on the mixture of the complex 1 with 3,5-DTBC and o-aminophenol separately. Fig. 15(a) and (b) illustrate the EPR spectra of the mixture containing complex 1 and 3,5-DTBC/o-aminophenol, respectively in acetonitrile medium. Both the EPR spectra is dominated by an isotropic signal around $g_{\text {iso }} \sim 2.00$ (for instance, $g_{\text {iso }}$ $=1.974$ in case of 3,5-DTBC and $g_{\text {iso }}=1.973$ in case of $o$-aminophenol), with a peak-to-peak line width of $c a .20 \mathrm{G}$. The $g$ value of the signal is very much closed to 2.0023 (value for a free electron $^{49}$ ), a value that is characteristic for organic radicals, such as a phenoxyl-type radical..$^{50}$ Hence it can be concluded that cobalt(III) tetrazolato complexes are capable of oxidizing 3,5-DTBC and $o$-aminophenol through a radical pathway, as shown in Schemes 3 and 4, respectively. 




(a)



(b)

Fig. 15 EPR spectra of acetonitrile solution of complex $1\left(10^{-4} \mathrm{M}\right)$ at $77 \mathrm{~K}$ immediately after addition of (a) 3,5-DTBC or (b) o-aminophenol.
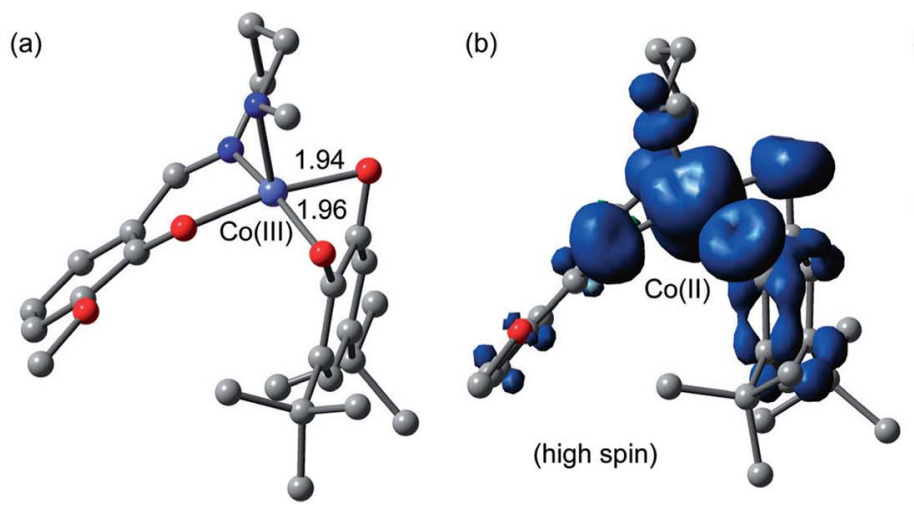

(c)

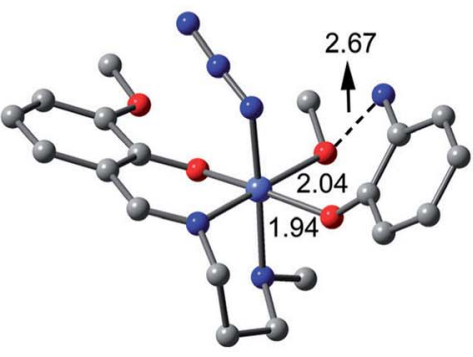

Fig. 16 (a) DFT optimized geometry of the complex between the 3,5-DTBC substrate and cobalt(II) metal center. (b) Spin density plot of the cobalt(II) complex (upon SET). (c) DFT optimized geometry of the complex between the OAPH substrate and cobalt(II) metal center. H-atoms omitted for clarity. Distances in $\AA$.

\section{Theoretical proof}

Catechol oxidase and phenoxazinone synthase mimicking activities have been extensively analyzed previously by theoretical studies. .g, $460,470,51$ Therefore, we have mainly focused in the theoretical study to analyze the energetic features of the supramolecular interactions and how they influence the crystal packing. However, in an effort to give some theoretical support to the mechanism and species proposed in the ESI-MS experiments, we have computed both cobalt(III) and cobalt(II) intermediates proposed in Scheme 3 using DFT calculations (BP86D3/def2-TZVP). The fully optimized geometries and spin density analysis of the cobalt(II) complex have been given in Fig. 16. The catechol is doubly coordinated to the cobalt(III) with similar Co $\cdots$ O distances. Upon the single electron transfer, the spin density plot reveals that the unpaired electron is equally distributed in both O-atoms and also the aromatic ring. The spin density at the cobalt(II) atom is $2.7 \mathrm{e}$, thus confirming the cobalt(II) oxidation state, with some spin density delocalized into the ligand (to the atoms directly bonded to cobalt). Finally, we have also optimized using DFT calculations the proposed complex $\left[\mathrm{Co}-\mathrm{L}^{1}-\mathrm{N}_{3}-(\mathrm{OAPH})-\mathrm{CH}_{3} \mathrm{OH}\right]$ as the first mechanistic step shown in Scheme 4 (see Fig. 16c). The substrate is monocoordinated to cobalt, and the $\mathrm{NH}_{2}$ group is H-bonded to the $\mathrm{MeOH}$ group $(\mathrm{O} \cdots \mathrm{N}$ distance $2.67 \AA)$.

\section{Concluding remarks}

Two new cobalt(III) tetrazolato complexes with Schiff bases and azide co-ligands have been synthesized under nonhydrothermal and non-microwave reaction conditions using a simple in situ 1,3-dipolar cycloaddition reaction. The simple domino synthesis of these complexes therefore opens a new convenient synthetic route for such types of cobalt(III) tetrazolato complexes with Schiff base and azide as co-ligands. The structures of the complexes were confirmed by single crystal Xray diffraction technique. The formation of hydrogen bonding and $\mathrm{C}-\mathrm{H} \cdots \pi$ interactions have been studied using DFT calculations. Catechol oxidase and phenoxazinone synthase mimicking activity of the complexes have been studied spectrophotometrically. Due to the similarity of molecular structures, the complexes show comparable results as far as catechol oxidase and phenoxazinone synthase activity. 


\section{Conflicts of interest}

There are no conflicts to declare.

\section{Acknowledgements}

K. G. expresses his gratitude to UGC, India, for awarding a Senior Research Fellowship (Sr. No. 2121410149; Roll No.: 132586; Ref. No.: 21/12/2014(ii)EU-V; Dated: 25.08.2015). Crystallographic data were collected at the DST-FIST, India funded Single Crystal Diffractometer Facility at the Department of Chemistry, Jadavpur University. A. F. and A. B. gratefully acknowledge the financial support of this work by the MINECO of Spain (project CTQ2014-57393-C2-1-P, FEDER funds). We thank the CTI (UIB) for free allocation of computer time.

\section{Notes and references}

1 (a) Y. Fu, F.-M. J. Chang and D. P. Giedroc, Acc. Chem. Res., 2014, 47, 3605-3613; (b) H. Zhu, J. Fan, B. Wang and X. Peng, Chem. Soc. Rev., 2015, 44, 4337-4366; (c) T. McKee and J. R. McKee, Biochemistry: An Introduction, McGraw-Hill Companies, Inc., China Science Press, New York, 2nd edn, 1999; (d) C. S. Bonnet and É. Tóth, Future Med. Chem., 2010, 2, 367-384; (e) C. K. Mathews and K. E. Van Holde, Biochemistry, The Benjamin/Cummings Publishing Company, Inc., Menlo Park, 2nd edn, 1996; (f) J. J. Braymer and D. P. Giedroc, Curr. Opin. Chem. Biol., 2014, 19, 59-66; (g) C. Blériot, M. Gault, E. Gueguen, P. Arnoux, D. Pignol, M. A. M. Berthelota and A. Rodrigue, Metallomics, 2014, 6, 1400-1409.

2 (a) D. A. Quist, D. E. Diaz, J. J. Liu and K. D. Karlin, J. Biol. Inorg Chem., 2017, 22, 253-188; (b) M. Can, F. A. Armstrong and S. W. Ragsdale, Chem. Rev., 2014, 114, 4149-4174; (c) H.-J. Thierse, S. Helm, M. Pink and H. U. Weltzien, J. Immunol. Methods, 2007, 328, 14-20; (d) M. M. Bernardo, S. Brown, Z. H. Li, R. Fridman and S. Mobashery, J. Biol. Chem., 2002, 277, 11201-11207; (e) P. A. Lindahl and M. J. Moore, Biochemistry, 2016, 55, 4140-4153.

3 (a) M. Hoaraua, C. Hureaua, E. Gras and P. Faller, Chem. Soc. Rev., 2016, 308, 445-459; (b) T. Ye, X. Bai, X. Jiang, Q. Wu, S. Chen, A. Qu, J. Huang, J. Shenc and W. Wu, Polym. Chem., 2016, 7, 2847-2857; (c) R. L. D'Ordine, R. S. Linger, C. J. Thai and V. J. Davisson, Biochemistry, 2012, 51, 57915803; (d) E. L. Kovrigin and J. P. Loria, Biochemistry, 2006, 45, 2636-2647.

4 (a) J. Fritsch, O. Lenz and B. Friedrich, J. Bacteriol., 2011, 193, 2487-2497; (b) K. S. Hewitson, L. A. McNeill, J. M. Elkins and C. J. Schofield, Biochem. Soc. Trans., 2003, 31, 510-515; (c) P. A. Cobine, F. Pierrel and D. R. Winge, Biochim. Biophys. Acta, 2006, 1763, 759-772.

5 (a) K. Ladomenou, G. Charalambidis and A. G. Coutsolelos, Inorg. Chim. Acta, 2010, 363, 2201-2208; (b) S. K. Dey and A. Mukherjee, Coord. Chem. Rev., 2016, 310, 80-115; (c) A. A. Vernekar, T. Das, S. Ghosh and G. Mugesh, Chem.Asian J., 2016, 11, 72-76; (d) T. Ueno, Angew. Chem., Int. Ed., 2010, 49, 3868-3869; (e) P. Chaudhuri, K. Wieghardt,
T. Weyhermüller, T. K. Paine, S. Mukherjee and C. Mukherjee, Biol. Chem., 2005, 386, 1023-1033.

6 (a) F. T. Ferre, J. A. L. C. Resende, J. Schultz, A. S. Mangrich, R. B. Faria, A. B. Rocha and M. Scarpellini, Polyhedron, 2017, 123, 293-304; (b) A. Panja, N. C. Jana, S. Adak and K. Pramanik, Inorg. Chim. Acta, 2017, 459, 113-123; (c) A. T. Fiedler and A. A. Fischer, J. Biol. Inorg Chem., 2017, 22, 407-424; (d) H. Yang, J. Zha, P. Zhang, Y. Qin, T. Chen and F. Ye, Sens. Actuators, B, 2017, B247, 469-478; (e) N. Sarkar, P. K. Bhaumik and S. Chattopadhyay, Polyhedron, 2016, 115, 37-46.

7 (a) F. Zippel, F. Ahlers, R. Werner, W. Haase, H. F. Nolting and B. Krebs, Inorg. Chem., 1996, 35, 3409-3419; (b) T. Kurahashi and H. Fujii, J. Am. Chem. Soc., 2011, 133, 8307-8316; (c) P. Setha, M. G. B. Drew and A. Ghosh, J. Mol. Catal. A: Chem., 2012, 365, 154-161; (d) M. Mondal, P. M. Guhaa, S. Giri and A. Ghosh, J. Mol. Catal. A: Chem., 2016, 424, 54-64; (e) C. Fernandes, A. Neves, A. J. Bortoluzzi, A. S. Mangrich, E. Rentschler, B. Szpoganicz and E. Schwingel, Inorg. Chim. Acta, 2001, 320, 12-21.

8 (a) M. L. Roes-Hill, C. Goodwin and S. Burton, Trends Biotechnol., 2009, 27, 248-268; (b) C. E. Barry, P. G. Nayar and T. P. Begley, Biochemistry, 1989, 28, 6323-6333; (c) A. W. Smith, A. Camara-Artigas, M. Wang, J. P. Allen and W. A. Francisco, Biochemistry, 2006, 45, 4378-4387.

9 (a) I. A. Koval, P. Gamez, C. Belle, K. Selmeczi and J. Reedijk, Chem. Soc. Rev., 2006, 35, 814-840; (b) R. Than, A. A. Feldmann and B. Krebs, Coord. Chem. Rev., 1999, 182, 211-241; (c) C. Gerdemann, C. Eicken and B. Krebs, Acc. Chem. Res., 2002, 35, 183-191; (d) K. Selmeczi, M. Reglier, M. Giorgi and G. Speier, Coord. Chem. Rev., 2003, 245, 191201; (e) N. Sarkar, M. Das and S. Chattopadhyay, Inorg. Chim. Acta, 2017, 457, 19-28; (f) A. Panja and P. Guionneau, Dalton Trans., 2013, 42, 5068-5075; $(g)$ N. Sarkar, K. Harms, A. Frontera and S. Chattopadhyay, New J. Chem., 2017, 41, 8053-8065.

10 (a) S. Kumar, D. N. Dhar and P. N. Saxena, J. Sci. Ind. Res., 2009, 68, 181-187; (b) T. Suzuki, T. Moriya, R. Endo and N. Iwasaki, Polym. Chem., 2017, 8, 761-768; (c) U. Schatzschneider, Eur. J. Inorg. Chem., 2010, 1451-1467.

11 (a) R. Bikas, H. H. Monfared, T. Lis and M. Siczek, Inorg. Chem. Commun., 2012, 15, 151-155; (b) A. H. Kianfar, M. Sedighipoor, G. Mohammadnezhad, H. Görls, W. Plass and M. Roushani, J. Iran. Chem. Soc., 2017, 14, 313-322; (c) S. K. Gupta, N. Sen, J. A. Ganaie, R. J. Butcher and J. P. Jasinski, J. Coord. Chem., 2017, 70, 3147-3170; (d) H. Iranmanesh, M. Behzad, G. Bruno, H. A. Rudbari, H. Nazari, A. Mohammadi and O. Taheri, Inorg. Chim. Acta, 2013, 395, 81-88.

12 (a) S. Shit, D. Saha, D. Saha, T. N. G. Row and C. Rizzoli, Inorg. Chim. Acta, 2014, 415, 103-110; (b) A. Nishinaga, T. Yamada, H. Fujisawa, K. Ishizaki, H. Ihara and T. Matsuura, J. Mol. Catal., 1988, 48, 249-264; (c) K. Maruyama, Y. Murakami, K. Yoda, T. Mashino and A. Nishinaga, J. Chem. Soc., Chem. Commun., 1992, 16171618. 
13 (a) A. Biswas, L. K. Das, M. G. B. Drew, G. Aromí, P. Gamez and A. Ghosh, Inorg. Chem., 2012, 51, 7993-8001; (b) P. Kavitha, M. R. Chary, B. V. V. A. Singavarapu and K. L. Reddy, J. Saudi Chem. Soc., 2016, 20, 69-80; (c) N. Shahabadi, S. Kashanian and F. Darabi, Eur. J. Med. Chem., 2010, 45, 4239-4245.

14 (a) A. D. Khalaji, M. Nikookar, K. Fejfarova and M. Dusek, J. Mol. Struct., 2014, 1071, 6-10; (b) A. D. Khalajia, R. Rahdaria, F. Ghariba, J. S. Matalobos and D. Das, J. Ceram. Process. Res., 2015, 16, 486-489; (c) L. Kafi-Ahmadi and L. Shirmohammadzadeh, J. Nanostruct. Chem., 2017, 7, 179-190.

15 (a) Q. Yang, X. Song, W. Zhang, L. hou, Q. Gong, G. Xie, Q. Wei, S. Chen and S. Gao, Dalton Trans., 2017, 46, 26262634; (b) A. Mrowiec, A. Jurowska, M. Hodorowicz and J. Szklarzewicz, Dalton Trans., 2017, 46, 4030-4037; (c) A. Gualandi, E. Matteucci, F. Monti, A. Baschieri, N. Armaroli, L. Sambri and P. G. Cozzi, Chem. Sci., 2017, 8, 1613-1620.

16 (a) C. C. Du, J. Z. Fan, X. F. Wang, S. B. Zhou and D. Z. Wang, J. Mol. Struct., 2017, 1133, 348-357; (b) X.-L. Wang, T.-J. Li, A.-X. Tian and N. Xu, Inorg. Chim. Acta, 2016, 443, 78-85; (c) J. Yang, J. Wang, B. Wei, L. Shen, Y.-T. Min, H.-J. Cheng, Y. Xu, J. Huang, C.-C. Wang, X. Zhang, M.-L. Wu, Q.-Y. Li and G.-W. Yang, Transition Met. Chem., 2016, 41, 35-43; (d) M. Taheriha, M. Ghadermazi and V. Amani, J. Mol. Struct., 2016, 1107, 57-65; (e) L. Shen1, M. J. Cao, F. F. Zhang, Q. Wu, L. Y. Zhao, Y. M. Lu, Q. Y. Li, G. W. Yang, B. Wei and J. H. Zou, Transition Met. Chem., 2016, 41, 125-131.

17 (a) R. Imai, S. Komeda, M. Shimura, S. Tamura, S. Matsuyama, K. Nishimura, R. Rogge, A. Matsunaga, I. Hiratani, H. Takata, M. Uemura, Y. Iida1, Y. Yoshikawa, J. C. Hansen, K. Yamauchi, M. T. Kanemaki and K. Maeshima, Sci. Rep., 2016, 6, 24712; (b) S. Kuwata and T. Ikariya, Chem. Commun., 2014, 50, 14290-14300; (c) G. E. Büchel, I. N. Stepanenko, M. Hejl, M. A. Jakupec, B. K. Keppler and V. B. Arion, Inorg. Chem., 2011, 50, 76907697; (d) B. C. Losantos, A. A. Krokhin, I. N. Stepanenko, R. Eichinger, M. A. Jakupec, V. B. Arion and B. K. Keppler, Inorg. Chem., 2007, 46, 5023-5033.

18 (a) P. Neves, A. B. Lysenko, A. C. Gomes, M. Pillinger, I. S. Gonçalves and A. A. Valente, Catal. Lett., 2017, 147, 1133-1143; (b) L. Peters, R. Fröhlich, A. S. F. Boyd and A. Kraft, J. Org. Chem., 2001, 66, 3291-3298; (c) M. Das, S. Chatterjee, K. Harms, T. K. Mondal and S. Chattopadhyay, Dalton Trans., 2014, 43, 2936-2947.

19 (a) B. G. Mukhopadhyay, S. Mukhopadhyay, M. F. C. G. da Silva, M. A. J. Charmier and A. J. L. Pombeiro, Dalton Trans., 2009, 4778-4785; (b) A. Hantzsch and A. Vagt, Justus Liebigs Ann. Chem., 1901, 314, 339-369; (c) R. Nasani, M. Saha, S. M. Mobin and S. Mukhopadhyay, Polyhedron, 2013, 55, 24-36.

20 (a) M. Das, K. Harms and S. Chattopadhyay, Dalton Trans., 2014, 43, 5643-5647; (b) R.-J. Xu, D.-W. Fu, J. Dai, Y. Zhang, J.-Z. Ge and H.-Y. Ye, Inorg. Chem. Commun., 2011, 14, 1093-1096; (c) A. D. Bond, A. Fleming, J. Gaire,
F. Kelleher, J. McGinley, V. McKee and U. Sheridan, Polyhedron, 2012, 33, 289-296; (d) Z.-H. Sun, L.-B. Meng and H. Lin, Acta Crystallogr., Sect. C: Cryst. Struct. Commun., 2009, E65, m280.

21 (a) G. M. Sheldrick, Acta Crystallogr., Sect. A: Fundam. Crystallogr., 2008, 64, 112-122; (b) G. M. Sheldrick, SHELXS-97 and SHELXL-97: Program for Structure Solution, University of Göttingen, Institute fur Anorganische Chemieder Universitat, Gottingen, Germany, 1997.

22 G. M. Sheldrick, SADABS: Software for Empirical Absorption Correction, University of Göttingen, Institute fur Anorganische Chemieder Universitat, Gottingen, Germany, 1999-2003.

23 (a) M. A. Spackman and D. Jayatilaka, CrystEngComm, 2009, 11, 19-32; (b) F. L. Hirshfeld, Theor. Chim. Acta, 1977, 44, 129-138; (c) H. F. Clausen, M. S. Chevallier, M. A. Spackman and B. B. Iversen, New J. Chem., 2010, 34, 193-199; (d) M. A. Spackman and P. G. Byrom, Chem. Phys. Lett., 1997, 267, 215-220.

24 (a) A. L. Rohl, M. Moret, W. Kaminsky, K. Claborn, J. J. McKinnon and B. Kahr, Cryst. Growth Des., 2008, 8, 4517-4525; (b) A. Parkin, G. Barr, W. Dong, C. J. Gilmore, D. Jayatilaka, J. J. McKinnon, M. A. Spackman and C. C. Wilson, CrystEngComm, 2007, 9, 648-652; (c) M. A. Spackman and J. J. McKinnon, CrystEngComm, 2002, 4, 378-392.

25 S. K. Wolff, D. J. Grimwood, J. J. McKinnon, D Jayatilaka, M. A. Spackman, Crystal Explorer 2.0; University of Western Australia: Perth, Australia, 2007. http:// hirshfeldsurfacenet.blogspot.com/.

26 (a) A. Bhattacharyya, S. Roy, J. Chakraborty and S. Chattopadhyay, Polyhedron, 2016, 112, 109-117; (b) S. Roy, T. Basak, S. Khan, M. G. B. Drew, A. Bauzá, A. Frontera and S. Chattopadhyay, ChemistrySelect, 2017, 2, 9336-9343; (c) T. Basak, K. Ghosh and S. Chattopadhyay, Polyhedron, 2018, 146, 81-92.

27 A. Bhattacharyya, A. Bauzá, A. Frontera and S. Chattopadhyay, Polyhedron, 2016, 119, 451-459.

28 R. Ahlrichs, M. Bär, M. Häser, H. Horn and C. Kölmel, Chem. Phys. Lett., 1989, 162, 165-169.

29 (a) A. Bauzá, A. Terrón, M. Barceló-Oliver, A.García-Raso and A. Frontera, Inorg. Chim. Acta, 2016, 452, 244-250; (b) D. Sadhukhan, M. Maiti, G. Pilet, A. Bauzá, A. Frontera and S. Mitra, Eur. J. Inorg. Chem., 2015, 11, 1958-1972; (c) M. Mirzaei, H. Eshtiagh-Hosseini, Z. Bolouri, Z. Rahmati, A. Esmaeilzadeh, A. Hassanpoor, A. Bauza, P. Ballester, M. Barceló-Oliver, J. T. Mague, B. Notash and A. Frontera, Cryst. Growth Des., 2015, 15, 1351-1361; (d) P. Chakraborty, S. Purkait, S. Mondal, A. Bauzá, A. Frontera, C. Massera and D. Das, CrystEngComm, 2015, 17, 4680-4690.

30 S. F. Boys and F. Bernardi, Mol. Phys., 1970, 19, 553-555.

31 Spartan '10, v. 1.1.0, Wavefunction Inc, Irvine CA, www.wavefun.com.

32 T. A. Keith, AIMAll (Version 17.01.25), Gristmill Software, Overland Park KS, USA, 2013.

33 (a) S. Roy, K. Harms and S. Chattopadhyay, Polyhedron, 2015, 91, 10-17; (b) A. Bhattacharyya, P. K. Bhaumik, P. P. Jana and 
S. Chattopadhyay, Polyhedron, 2014, 78, 40-45; (c) W.-J. Lian, X.-T. Wang, C.-Z. Xie, H. Tian, X.-Q. Song, H.-T. Pan, X. Qiao and J.-Y. Xu, Dalton Trans., 2016, 45, 9073-9087.

34 M. Das, K. Harms, B. N. Ghosh, K. Rissanen and S. Chattopadhyay, Polyhedron, 2015, 87, 286-292.

35 (a) S. Chattopadhyay, G. Bocelli, A. Musatti and A. Ghosh, Inorg. Chem. Commun., 2006, 9, 1053-1057; (b) L. Pogány, J. Moncol, M. Gál, I. Šalitroš and R. Boča, Inorg. Chim. Acta, 2017, 462, 23-29; (c) K. Ghosh, A. Banerjee, S. Roy, A. Bauzá, A. Frontera and S. Chattopadhyay, Polyhedron, 2016, 112, 86-95.

36 (a) J. Müller, C. Würtele, O. Walter and S. Schindler, Angew. Chem., Int. Ed., 2007, 46, 7775-7777; (b) D. Bandyopadhyay, M. Layek, M. Fleck, R. Saha and C. Rizzoli, Inorg. Chim. Acta, 2017, 461, 174-182; (c) H. A. Rudbari, M. R. Iravani, V. Moazam, B. Askari, M. Khorshidifard, N. Habibi and G. Bruno, J. Mol. Struct., 2016, 1125, 113-120.

37 (a) D. Cremern and J. A. Pople, J. Am. Chem. Soc., 1975, 97, 1354-1358; (b) N. Nishio, Phys. Chem. Chem. Phys., 2011, 13, 13873-13900; (c) H. Suezawa, T. Yuzuri, Y. Kohno, Y. Yamaguchi and M. Asami, Bull. Chem. Soc. Jpn., 2010, 83, 802-808; (d) M. Nishio, Y. Umezawa, J. Fantini, M. S. Weiss and P. Chakrabarti, Phys. Chem. Chem. Phys., 2014, 16, 12648-12683; (e) M. Nishio, J. Mol. Struct., 2012, 1018, 2-7.

38 (a) M. A. Spackman and P. G. Byrom, Chem. Phys. Lett., 1997, 267, 215-220; (b) S. Roy and S. Chattopadhyay, Inorg. Chim. Acta, 2015, 433, 72-77; (c) M. Das and S. Chattopadhyay, Polyhedron, 2013, 50, 443-451; (d) T. Basak, K. Ghosh, C. J. Gómez-García and S. Chattopadhyay, Polyhedron, 2018, 146, 42-54.

39 (a) B. K. Shaw, M. Das, A. Bhattacharyya, B. N. Ghosh, S. Roy, P. Mandal, K. Rissanen, S. Chattopadhyay and S. K. Saha, RSC Adv., 2016, 6, 22980-22988; (b) P. Schmid, M. Maier, H. Pfeiffer, A. Belz, L. Henry, A. Friedrich, F. Schönfeld, K. Edkins and U. Schatzschneider, Dalton Trans., 2017, 46, 13386-13396.

40 (a) M. Das, B. K. Shaw, B. N. Ghosh, K. Rissanen, S. K. Saha and S. Chattopadhyay, RSC Adv., 2015, 5, 46869-46872; (b) M. Das, K. Harms, B. N. Ghosh, K. Rissanen and S. Chattopadhyay, Polyhedron, 2015, 87, 286-292; (c) S. Roy, K. Harms, A. Bauzá, A. Frontera and S. Chattopadhyay, Polyhedron, 2017, 121, 199-205; (d) K. Ghosh, K. Harms, A. Bauzá, A. Frontera and S. Chattopadhyay, Dalton Trans., 2018, 47, 331-347.

41 (a) P. K. Bhaumik, S. Roy, K. Harms and S. Chattopadhyay, Polyhedron, 2014, 81, 168-179; (b) S. Bhattacharya, S. Roy and S. Chattopadhyay, J. Coord. Chem., 2016, 69, 915-925.

42 S. Chattopadhyay, M. G. B. Drew and A. Ghosh, Eur. J. Inorg. Chem., 2008, 1693-1701.

43 A. Kufelnicki, S. V. Tomyn, Y. S. Moroz, M. Haukka, J. J. Rosińska and I. O. Fritsky, Polyhedron, 2012, 33, 410-416.

44 (a) M. Galini, M. Salehi, M. Kubicki, A. Amiri and A. Khaleghian, Inorg. Chim. Acta, 2017, 461, 167-173; (b) A. H. Kianfar, W. A. K. Mahmood, M. Dinari, M. H. Azarian and F. Z. Khafri, Spectrochim. Acta, Part A, 2014, 127, 422-428.
45 (a) K. Ghosh, K. Harms and S. Chattopadhyay, Polyhedron, 2017, 123, 162-175; (b) A. Bottcher, T. Takeuchi, K. I. Hardcastle, T. J. Meade and H. B. Gray, Inorg. Chem., 1997, 36, 2498-2504; (c) A. A. Khandar, B. Shaabani, F. Belaj and A. Bakhtiari, Polyhedron, 2006, 25, 1893-1900; (d) M. Salehi and M. Hasanzadeh, Inorg. Chim. Acta, 2015, 426, 6-14.

46 (a) M. Das, B. N. Ghosh, A. Bauzá, K. Rissanen, A. Frontera and S. Chattopadhyay, RSC Adv., 2015, 5, 73028-73039; (b) A. Panja, M. Shyamal, A. Saha and T. K. Mandal, Dalton Trans., 2014, 43, 5443-5452; (c) N. Sarkar, K. Harms, A. Bauzá, A. Frontera and S. Chattopadhyay, ChemistrySelect, 2017, 2, 2975-2984; (d) M. Mitra, T. Kundu, G. Kaur, G. Sharma, A. R. Choudhury, Y. Singh and R. Ghosh, RSC Adv., 2016, 6, 58831-58838.

47 (a) M. Mitra, P. Raghavaiah and R. Ghosh, New J. Chem., 2015, 39, 200-205; (b) X.-Y. Li, L. Chen, L. Gao, Y. Zhang, S. F. Akogun and W.-K. Dong, RSC Adv., 2017, 7, 3590535916; (c) T. S. Mahapatra, D. Basak, S. Chand, J. Lengyel, M. Shatruk, V. Bertolasic and D. Ray, Dalton Trans., 2016, 45, 13576-13589; (d) M. I. Ayad, Arabian J. Chem., 2016, 9, S1297-S1306; (e) S. K. Dey and A. Mukherjee, New J. Chem., 2014, 38, 4985-4995; (f) S. K. Dey, P. Mitra and A. Mukherjee, Cryst. Growth Des., 2015, 15, 706-717; $(g)$ S. K. Dey and A. Mukherjee, J. Mol. Catal. A: Chem., 2015, 407, 93-101; (h) J.-H. Qiu, Z.-R. Liao, X.-G. Meng, L. Zhu, Z.-M. Wang and K.-B. Yu, Polyhedron, 2005, 24, 1617-1623; (i) D. Dey, A. B. Roy, A. Ranjani, L. Gayathri, S. Chandraleka, D. Dhanasekaran, M. A. Akbarsha, C.-Y. Shen, H.-L. Tsai, M. Maji, N. Kole and B. Biswas, J. Chem. Sci., 2015, 127, 649-661; (j) L. Mandal, S. Sasmal, H. A. Sparkes, J. A. K. Howard and S. Mohanta, Inorg. Chim. Acta, 2014, 412, 38-45; (k) R. Modak, Y. Sikdar, S. Mandal and S. Goswami, Inorg. Chem. Commun., 2013, 37, 193-196; (l) S. Majumder, S. Mondal, P. Lemoine and S. Mohanta, Dalton Trans., 2013, 42, 4561-4569; (m) A. Banerjee, A. Guha, J. Adhikary, A. Khan, K. Manna, S. Dey, E. Zangrando and D. Das, Polyhedron, 2013, 60, 102-109; (n) L. Mandal and S. Mohanta, Dalton Trans., 2014, 43, 15737-15751; (o) A. Hazari, L. Kanta Das, R. M. Kadam, A. Bauza, A. Frontera and A. Ghosh, Dalton Trans., 2015, 44, 3862-3876; (p) P. Chakraborty and S. Mohanta, Inorg. Chim. Acta, 2015, 435, 38-45; (q) A. K. Maji, A. Chatterjee, S. Khan, B. K. Ghosh and R. Ghosh, J. Mol. Struct., 2017, 1146, 821-827; (r) K. Ghosh, K. Harms and S. Chattopadhyay, ChemistrySelect, 2017, 2, 8207-8220.

48 (a) A. Hazari, A. Das, P. Mahapatra and A. Ghosh, Polyhedron, 2017, 134, 99-106; (b) A. Panja, N. C. Janaa and P. Brandão, New J. Chem., 2017, 41, 9784-9795; (c) A. Panja and A. Frontera, Eur. J. Inorg. Chem., 2018, 924-931; (d) M. Mitra and R. Ghosh, Indian J. Chem., Sect. A: Inorg., Bioinorg., Phys., Theor. Anal. Chem., 2016, 55A, 681-685; (e) M. Mahato, D. Mondal and H. P. Nayek, ChemistrySelect, 2016, 1, 6777-6782; (f) A. Panja, Dalton Trans., 2014, 43, 7760-7770; (g) A. Panja, Polyhedron, 2014, 80, 81-89; (h) K. Ghosh, S. Roy, A. Ghosh, A. Banerjee, A. Bauzá, 
A. Frontera and S. Chattopadhyay, Polyhedron, 2016, 112, 617.

49 P. H. Rieger, in Electron Spin Resonance: Analysis and Interpretation; Royal Society of Chemistry, Cambridge, U.K., 2007.

50 (a) K. Ghosh, M. G. B. Drew and S. Chattopadhyay, Inorg. Chim. Acta, 2018, 482, 23-33; (b) A. Biswas, L. K. Das, M. G. B. Drew, G. Aromí, P. Gamez and A. Ghosh, Inorg. Chem., 2012, 51, 7993-8001; (c) R. Wanke, L. Benisvy,
M. L. Kuznetsov, M. F. C. Guedes da Silva and A. J. L. Pombeiro, Chem.-Eur. J., 2011, 17, 11882-11892.

51 (a) P. Chakraborty, J. Adhikary, B. Ghosh, R. Sanyal, S. K. Chattopadhyay, A. Bauzá, A. Frontera, E. Zangrando and D. Das, Inorg. Chem., 2014, 53, 8257-8269; (b) P. Adak, B. Ghosh, A. Bauzá, A. Frontera, A. J. Blake, M. Corbella, C. D. Mukhopadhyay and S. K Chattopadhyay, RSC Adv., 2016, 6, 86851-86861; (c) S. Dasgupta, I. Majumder, P. Chakraborty, E. Zangrando, A. Bauzá, A. Frontera and D. Das, Eur. J. Inorg. Chem., 2017, 133-145. 